Research Article

\title{
Experimental Study on the Saturated Compacted Loess Permeability under $K_{0}$ Consolidation
}

\author{
Yan-zhou Hao $\mathbb{D}^{1},{ }^{1}$ Tie-hang Wang, ${ }^{1}$ Xin Jin, ${ }^{1}$ Lei Cheng, ${ }^{2}$ and Jiang-le $\mathrm{Li}^{1}$ \\ ${ }^{1}$ College of Civil Engineering, Xi' an University of Architecture and Technology, Xi'an, Shaanxi 710055, China \\ ${ }^{2}$ College of Engineering Management and Real Estate, Henan University of Economics and Law, Zhengzhou, \\ Henan 450046, China \\ Correspondence should be addressed to Yan-zhou Hao; 30010508@hncj.edu.cn
}

Received 16 September 2019; Revised 11 December 2019; Accepted 12 December 2019; Published 29 February 2020

Academic Editor: Robert Černý

Copyright (c) 2020 Yan-zhou Hao et al. This is an open access article distributed under the Creative Commons Attribution License, which permits unrestricted use, distribution, and reproduction in any medium, provided the original work is properly cited.

This paper investigates the permeability characteristics of compacted loess by focusing on the anisotropy parallel and perpendicular to the compaction. Three tests are conducted on compacted loess: triaxial permeability test under confining pressure consolidation, triaxial permeability test under $K_{0}$ consolidation, and SEM test. Samples are maintained and tested at different dry densities under saturated conditions. The test results show that the saturated permeability coefficient of compacted loess is exponentially related to the initial dry density under both confining pressure consolidation and $K_{0}$ consolidation. The fitting equation can estimate the saturated permeability coefficient of compacted loess at different depths. The horizontal saturated permeability coefficient of compacted loess is larger than that in the vertical direction, showing obvious anisotropy. The saturated permeability anisotropy ratio is linearly related to the initial dry density. Comparing and analysing the saturated permeability coefficient, the saturated permeability coefficient of compacted loess under the $K_{0}$ consolidation condition is smaller than that under the confining pressure consolidation condition. Under the condition of $K_{0}$ consolidation, the connectivity of vertical and horizontal pores of compacted loess is weakened, the tortuosity is strengthened, and the void ratio is decreased. $K_{0}$ consolidation makes the flake-, plate-, and needle-like particles in compacted loess rotate continuously parallel to the compaction surface, which enhances the orientation of particles and leads to the saturated permeability anisotropy increase. The research results provide the basis for water field analysis in loess filling engineering.

\section{Introduction}

Large-scale hill-cutting and gully-filling and artificial landbuilding projects have been carried out successively in the loess area in China. In addition, highway, railway, and airport construction in loess areas requires filling to make up for the shortage of the construction land. Compaction is the primary method employed to improve the mechanical properties of compacted loess and prepare loess-filled construction sites. Permeability is an important property of loess. Water infiltration weakens compacted loess; therefore, examining the permeability of compacted loess is of great significance to large-scale filling foundations, roadbeds, and slopes in loess areas in China.

Consolidation under confining pressure simplifies the stress state of the soil sample in situ to three-dimensional equal stress action, which simplifies the operation of the test, but the stress state of the soil sample does not conform to the actual situation, which will cause errors in the analysis of the water field in soil. $K_{0}$ consolidation is a consolidation process in which only axial strain occurs and no radial strain occurs under confining pressure and axial deviator stress, which is in accordance with the actual stress state of soil samples in the soil layer. At present, the study of soil permeability is mainly based on the triaxial permeability test. The soil samples of the triaxial permeability test are consolidated under isobaric conditions in all directions, which is inconsistent with the actual initial stress state of natural soil layer $K_{0}$ consolidation.

There are few studies on soil triaxial permeability and a lack of systematization under $K_{0}$ consolidation. Most studies focus on the permeability of sand and other soils under confining pressure consolidation. The hydraulic conductivity 
and the coefficient of consolidation of sands with $25 \%$ silt content are approximately two orders of magnitude smaller than those of clean sands at effective confining stresses of $50-300 \mathrm{kPa}$ [1]. The saturated soil hydraulic conductivity is predicted from models by triaxial permeability test data under confining pressure consolidation $[2,3]$. The saturated hydraulic conductivity of poorly graded sands with nonplastic silt was obtained by using a flexible wall permeameter [4]. The particle shape and packing density characteristics of sand or sand-silt mixtures affected the hydraulic conductivity during in situ testing and in estimating soil behavior in a number of other capacities $[5,6]$. The saturated hydraulic conductivity of the sand-silt mixtures was obtained by triaxial tests at an effective confining pressure of $100 \mathrm{kPa}$ to establish the relationship between the undrained shear strength and the saturated hydraulic conductivity and discussed the effect of the percentage of low plastic fines and void ratio of the soil [7]. Li [8] studied the relationship between permeability and porosity in loess. The permeability coefficient is affected by dry density $[9,10]$, dry-wet cycle $[11]$, permeability time, confining pressure, structure [12], and osmotic pressure [13]. The permeability coefficient function of remolded unsaturated loess was established under varying humidity and density [14]. The above studies were conducted using conventional permeability tests.

Natural soils are generally considered to be in the state of $K_{0}$ consolidation $[15,16] . K_{0}$ is defined as the ratio of the lateral effective stress to the vertical effective stress under the condition that no deformation occurs in the lateral direction of the soil. The study of the permeability of soil is generally carried out under the condition of triaxial confining pressure consolidation, after that the pore structure of soil is different from that under the condition of $K_{0}$ consolidation, which inevitably leads to the difference of permeability of soil. The permeability of soil under the in situ stress state ( $K_{0}$ state) can better reflect the actual situation of water seepage in soil. Under the condition of triaxial equal confining pressure consolidation, the study of the permeability of soil is not consistent with the actual stress state of soil, which will inevitably produce some errors in the study of the distribution of the water field in soil. Therefore, it is of great practical significance to study the permeability of soil under the triaxial stress state under $K_{0}$ consolidation.

The tests of soil samples under $K_{0}$ consolidation are mostly focused on the effects of $K_{0}$ consolidation on the mechanical properties and deformation properties of different types of soils [17-31]. There are few reports on triaxial permeability of compacted loess under $K_{0}$ consolidation. Therefore, in this paper, the saturated triaxial permeability tests under confining pressure and $K_{0}$ consolidation are carried out for compacted loess samples with different dry densities and different consolidation confining pressure to obtain the permeability coefficients. Through comparative analysis of the permeability coefficient, the difference of saturated permeability of compacted loess under $K_{0}$ consolidation and confining pressure consolidation is obtained. The research contents are of great significance to the analysis of the water field in compacted loess.

\section{Test Scheme}

2.1. Samples. Soil samples used in this study were $Q_{3}$ Malan loess collected from a foundation pit in Xi'an, China. Malan loess is yellowish brown, relatively weak, and wet. The physical properties of loess samples were determined following the Chinese National Standards GB/T50123-1999 [32]. The grain size distribution curve is shown in Figure 1. The soil sample is silty clay, in which the content of silt particles reaches $63.8 \%$ (Table 1 and Figure 1).

According to laboratory compaction tests following the Chinese National Standards GB/T50123-1999 [32], the optimal soil sample moisture content was $18.9 \%$ and the maximum dry density was $1.73 \mathrm{~g} / \mathrm{cm}^{3}$. Soil samples from the soil layer were naturally air-dried and then pulverized using a rubber hammer, which separated the cemented particles only but did not damage the loess particles. The pulverized loess was sieved through a $2 \mathrm{~mm}$ mesh in order to prepare soil samples with a moisture content of $18.9 \%$, which were sealed for more than 48 hours to produce the desired water distribution. Samples were prepared using a specifically designed sample press. Wet soil was weighed based on the dry density and moisture content and was compacted vertically into five layers. Samples were $150 \mathrm{~mm}$ in diameter and $112 \mathrm{~mm}$ in height (Figure 2). The dry density was $1.40 \mathrm{~g} / \mathrm{cm}^{3}$, $1.50 \mathrm{~g} / \mathrm{cm}^{3}, 1.60 \mathrm{~g} / \mathrm{cm}^{3}$, and $1.70 \mathrm{~g} / \mathrm{cm}^{3}$. The error was controlled to be $\leq 0.02 \mathrm{~g} / \mathrm{cm}^{3}$.

Soil samples were collected in the direction of vertical compaction (called vertical samples) and parallel to the compaction surface (called horizontal samples) (Figure 2). The first group of samples: triaxial permeability test samples under confining pressure consolidation, was cut out using a soil cutting plate, and the samples were $39.1 \mathrm{~mm}$ in diameter and $80 \mathrm{~mm}$ in height (Figure 2). The number of samples is four vertical and four horizontal samples. The second group of samples: triaxial permeability test samples under $K_{0}$ consolidation, was cut out using a soil cutting plate, and the samples were $39.1 \mathrm{~mm}$ in diameter and $80 \mathrm{~mm}$ in height (Figure 2). The number of samples is four vertical samples. The third group of samples: the compacted loess sample, was first consolidated by the $K_{0}$ state and then cut into $39.1 \mathrm{~mm}$ in diameter and $80 \mathrm{~mm}$ in height along the horizontal direction on the cutting plate. The number of samples is horizontal samples. All samples were put into a vacuum saturation device for saturation treatment until the saturation was greater than $95 \%$.

\subsection{Testing Techniques}

2.2.1. Triaxial Permeability Test. The triaxial permeability test for saturated compacted loess was done using an SLB-1 triaxial permeameter (Figure 3). The first group of samples was consolidated under the confining pressure $\sigma_{3}$ of $100 \mathrm{kPa}$, $200 \mathrm{kPa}, 300 \mathrm{kPa}$, and $400 \mathrm{kPa}$ and kept confining pressure unchanged to determine the saturated permeability coefficient $k$ of compacted loess. The second group of samples was consolidated at the $K_{0}$ state under the confining pressure $\sigma_{3}$ of $100 \mathrm{kPa}, 200 \mathrm{kPa}, 300 \mathrm{kPa}$, and $400 \mathrm{kPa}$ and kept the $K_{0}$ state unchanged to determine the saturated permeability coefficient 


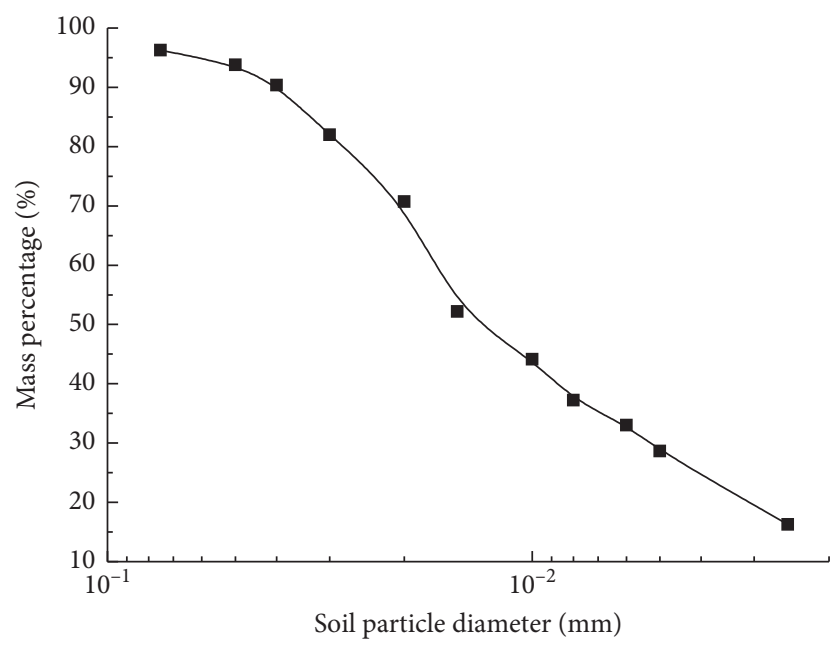

Figure 1: Grain size distribution curve.

TABle 1: Physical properties of loess.

\begin{tabular}{lcccccc}
\hline $\begin{array}{l}\text { Relative density } \\
G_{S}\end{array}$ & $\begin{array}{c}\text { Liquid limit } W_{L} \\
(\%)\end{array}$ & $\begin{array}{c}\text { Plastic limit } W_{P} \\
(\%)\end{array}$ & $\begin{array}{c}\text { Plasticity index } \\
I_{p}\end{array}$ & \multicolumn{3}{c}{ Particle composition (\%) } \\
\hline 2.72 & 30.8 & 18.6 & 12.2 & 3.72 & 52.18 & 15.44 \\
\hline
\end{tabular}
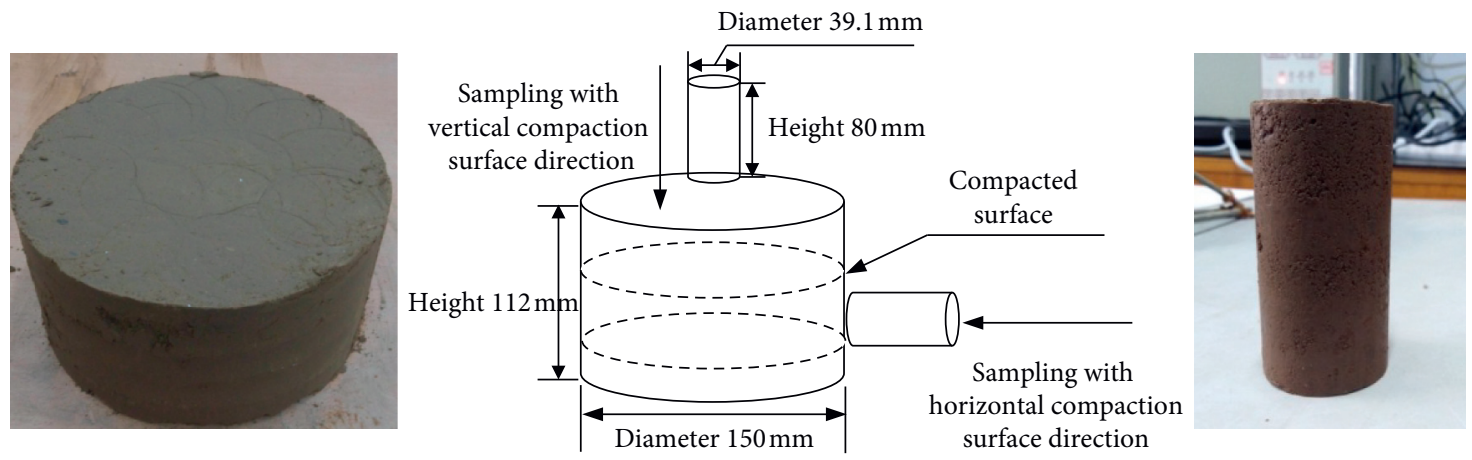

Figure 2: Sample of compacted loess and sampling direction.

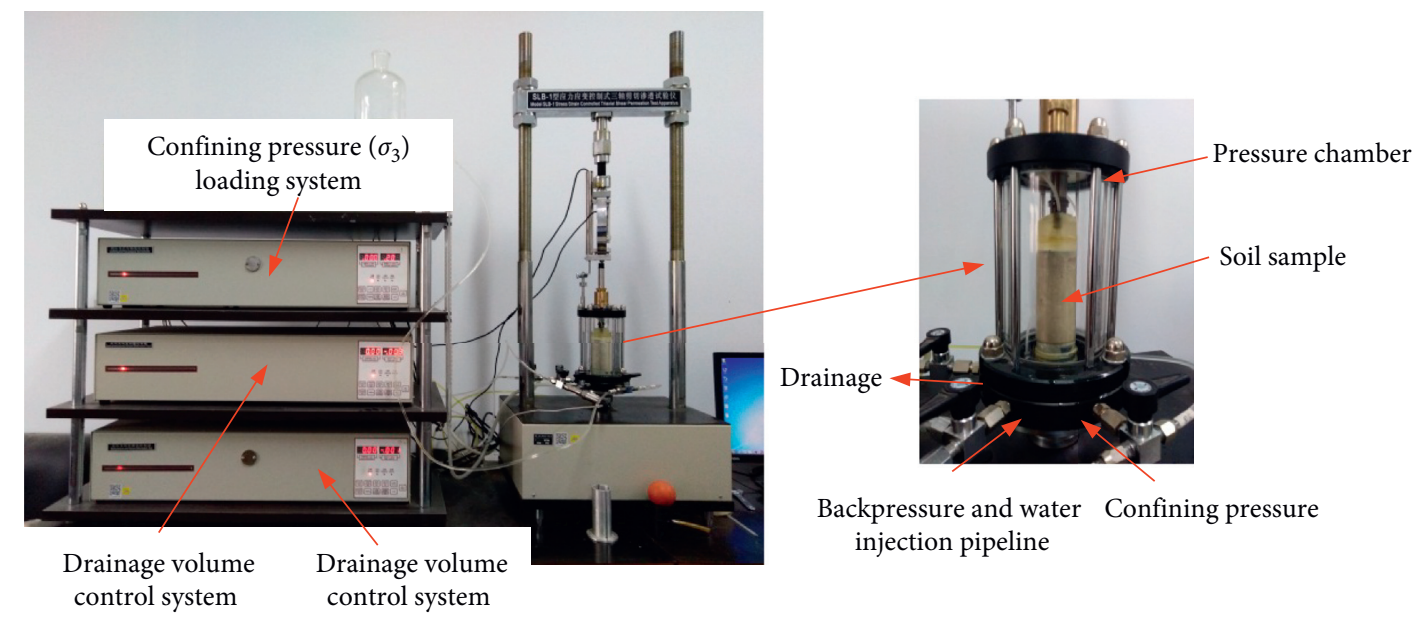

FIgURE 3: SLB-1 triaxial permeameter test apparatus. 
$k_{s}$ of compacted loess. Because the triaxial permeameter could not realize the stress state of the soil sample taken in the horizontal direction (Figure 4), the compacted soil sample with a diameter of $150 \mathrm{~mm}$ and height of $112 \mathrm{~mm}$ was consolidated with the $K_{0}$ state under the confining pressure of $100 \mathrm{kPa}$, $200 \mathrm{kPa}, 300 \mathrm{kPa}$, and $400 \mathrm{kPa}$. After consolidation, the specimen was cut into $39.1 \mathrm{~mm}$ in diameter and $80 \mathrm{~mm}$ in height parallel to the compacted surface. The sample as the third group was put into the triaxial permeameter to determine the saturated permeability coefficient $k_{s}$. Consolidation ended when the pore water pressure dissipated more than 95\% [32].

2.2.2. SEM Test. The SEM test was done using a scanning electron microscope (Figure 5) to collect microimages of soil samples. The samples for the scanning electron microscope (SEM) test were cut along the direction of the vertical compaction surface and horizontal compaction surface into $5 \mathrm{~mm}$ in length, $5 \mathrm{~mm}$ in width, and $10 \mathrm{~mm}$ in height with the dry densities of $1.40 \mathrm{~g} / \mathrm{cm}^{3}, 1.50 \mathrm{~g} / \mathrm{cm}^{3}, 1.60 \mathrm{~g} / \mathrm{cm}^{3}$, and $1.70 \mathrm{~g} /$ $\mathrm{cm}^{3}$. Four vertical and horizontal samples were used in the scanning electron microscope test. The samples were broken to be in $5 \mathrm{~mm}$ height and formed a relatively flat and fresh section. The loose particles were blown off the surface. The surface was coated with a metal film. Then, the sample was put into the SEM to take 500-fold magnification SEM images.

\section{Analysis of Test Results}

3.1. Saturated Permeability of Compacted Loess under Confining Pressure Consolidation. The saturated permeability coefficient of compacted loess decreased with the increasing initial dry density under the same consolidation confining pressure and decreased with the increasing consolidation confining pressure under the same initial dry density (Table 2). The saturated compacted loess horizontal saturated permeability coefficient $\left(k_{s h}\right)$ and vertical permeability coefficient $\left(k_{s v}\right)$ varied significantly for different initial dry densities. The horizontal permeability coefficient was larger than the vertical permeability coefficient, showing obvious anisotropy. During vertical compaction, macropores were destroyed and filled with soil particles, producing numerous small pores. The permeability of compacted loess in different compaction directions was mainly affected by its porosity and pore connectivity. The porosity was larger, the pore connectivity was better, and the permeability coefficient was greater, and it was smaller conversely. Flake and needle particles rotated to be parallel to the compaction surface after vertical compaction. The directionality of the particles, such as flakes and needles, weakened the porosity and connectivity of the pores perpendicular to the compaction surface. On the contrary, the porosity and connectivity of pores parallel to the compaction surface were improved. In addition, there were flaky clay minerals in the compacted loess. During the compaction process, the flaky clay minerals rotated continuously and finally parallel to the compacted surface. The increasing area of clay mineral particles blocked the connectivity of vertical pores which ultimately led to a reduction in the vertical permeability coefficient.

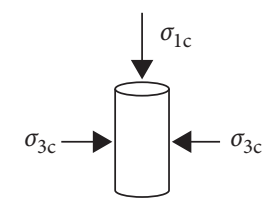

Sampling with vertical compaction surface direction

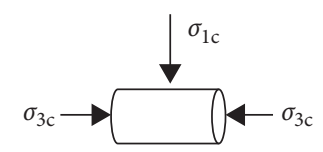

Sampling with horizontal compaction surface direction
Figure 4: Stress state of compacted loess.

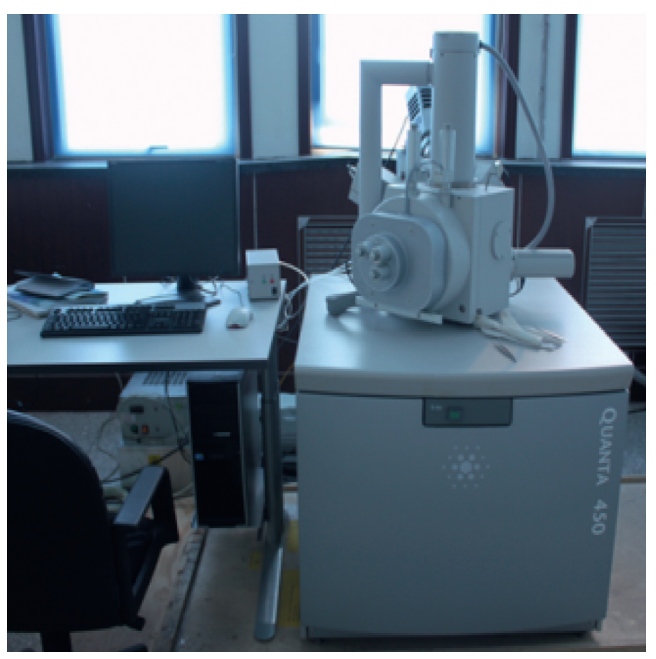

(a)

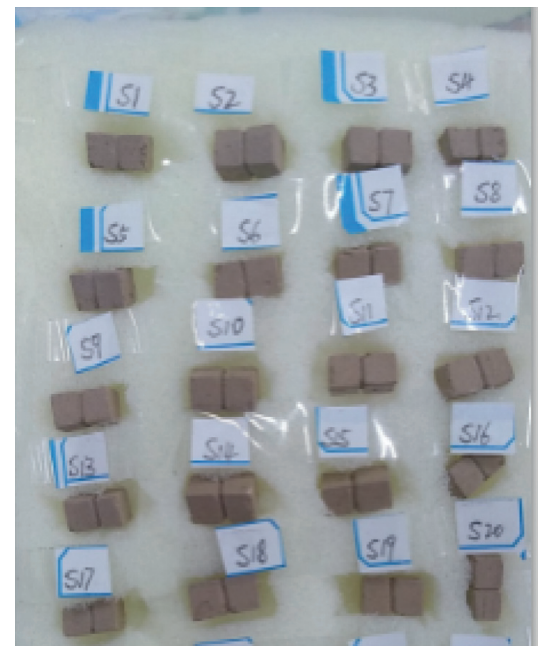

(b)

FIgURE 5: Scanning electron microscope and samples.

The relationship between the saturated permeability coefficient and the initial dry density follows the exponential equation (1) and the relationship between the saturated permeability coefficient and the consolidation confining pressure follows the exponential equation (2), which were determined using nonlinear regression analysis and the least-squares method in MATLAB software. The exponential functions were

$$
\begin{aligned}
& k_{s}=e^{a \cdot \rho_{d}^{2}+b \cdot \rho_{d}+c}, \\
& k_{s}=e^{a^{\prime} \cdot \sigma_{3}^{2}+b^{\prime} \cdot \sigma_{3}+c^{\prime}},
\end{aligned}
$$


TABLE 2: Permeability coefficient of saturated compacted loess under confining pressure.

\begin{tabular}{lcccccrrrr}
\hline & \multicolumn{3}{c}{ Saturated permeability coefficient $k_{s}\left(10^{-6} \mathrm{~cm} / \mathrm{s}\right)$} \\
Initial dry density $\rho_{d}\left(\mathrm{~g} / \mathrm{cm}^{3}\right)$ & \multicolumn{2}{c}{$100 \mathrm{kPa}$} & \multicolumn{2}{c}{$200 \mathrm{kPa}$} & \multicolumn{2}{c}{$300 \mathrm{kPa}$} & $k_{s v}$ & $k_{s h}$ & $k_{s v}$ \\
& $k_{s h}$ & $k_{s v}$ & $k_{s h}$ & $k_{s v}$ & $k_{s h}$ & 0.167 \\
1.70 & 3.503 & 1.873 & 1.203 & 0.726 & 0.506 & 0.329 & 0.247 \\
1.60 & 5.076 & 3.808 & 1.739 & 1.196 & 0.707 & 0.520 & 0.333 & 0.264 \\
1.50 & 6.403 & 4.580 & 2.150 & 1.631 & 0.969 & 0.794 & 0.428 & 0.374 \\
1.40 & 8.170 & 6.997 & 3.727 & 3.434 & 1.304 & 1.251 & 0.626 & 0.614 \\
\hline
\end{tabular}

where $k_{s}$ represents the saturated permeability coefficient $(\mathrm{cm} / \mathrm{s}) ; a, b, c, a^{\prime}, b^{\prime}$, and $c^{\prime}$ represent fitting parameters; $\rho_{d}$ represents the initial dry density $\left(\mathrm{g} / \mathrm{cm}^{3}\right)$; and $\sigma_{3}$ represents the consolidation confining pressure $(\mathrm{kPa})$.

Experimental data (Table 2) were fitted according to equations (1) and (2). Fitting parameters are shown in Tables 3 and 4, and the fitting curves are shown in Figures 6 and 7 .

(1) The saturated permeability coefficient of compacted loess was exponentially related to its initial dry density and consolidation confining pressure (Figures 6 and 7). Equations (1) and (2) were highly correlated with the fitting of the test data. The fitting equation (Tables 3 and 4) could be used to estimate saturated permeability coefficients of compacted loess with different initial dry densities and different depths $(0 \sim 20.2 \mathrm{~m}$, determined by the maximum confining pressure consolidation $400 \mathrm{kPa}$ and the density $2.0213 \mathrm{~g} / \mathrm{cm}^{3}$ of the compacted loess in this paper), providing a basis for the analysis of the water field in loess filling engineering.

(2) Under the same consolidation confining pressure, the saturated permeability coefficient in both vertical and horizontal directions decreased with the increasing initial dry density. When the initial dry density was close to the maximum dry density $\left(1.73 \mathrm{~g} / \mathrm{cm}^{3}\right)$, the saturated permeability coefficient was the smallest. The difference of permeability coefficient in the direction of the vertical compaction surface and horizontal compaction surface was obvious, and the difference increased with the increasing dry density (Figure 6).

(3) When the initial dry density of soil was small, pores between soil particles were composed of primarily large and medium trellis pores between aggregates in pointto-surface contact and line-to-surface contact, the pore connectivity was better, and the soil permeability coefficient was larger. With the increasing initial dry density, trellis pores were gradually compacted to form medium and small pores in line-surface contact and surface-surface contact. Pore connectivity and soil permeability coefficient decreased. When $\rho_{\mathrm{d}}=1.70 \mathrm{~g} /$ $\mathrm{cm}^{3}$ (compaction degree: 98\%), pores were dominated by micropores, particles were primarily in surface-tosurface contact, and pore connectivity and soil permeability coefficient were minimized.
(4) Under the same initial dry density, the saturated permeability coefficient decreased with the increasing consolidation confining pressure. When the consolidation confining pressure was high $\left(\sigma_{3}=400 \mathrm{kPa}\right)$, the saturated permeability coefficient was relatively small and had little variation (Figure 7). The difference of the permeability coefficient between the direction of the vertical compaction surface and that of the horizontal compaction surface decreased with the increasing confining pressure.

(5) With the increasing consolidation confining pressure, porosity and pore connectivity decreased gradually, the loess became more compact, and the saturated permeability coefficient of compacted loess decreased gradually.

The ratio of the permeability coefficient $k_{s h}$ to $k_{s v}$ was defined as the saturated permeability anisotropy ratio $r_{k s}$, which was used to characterize saturated permeability anisotropy of soils [33-36]:

$$
r_{k s}=\frac{k_{s h}}{k_{s v}}
$$

where $r_{k s}$ represents the saturated permeability anisotropy ratio; $k_{s h}$ represents the horizontal saturated permeability coefficient $(\mathrm{cm} / \mathrm{s})$; and $k_{s v}$ represents the vertical saturated permeability coefficient $(\mathrm{cm} / \mathrm{s})$.

The permeability coefficients (Table 2) of saturated compacted loess obtained from the triaxial permeability test were calculated by equation (3), and the permeability anisotropy ratios are shown in Table 5.

The permeability anisotropy ratio of compacted loess increased with the increasing initial dry density under the same consolidation confining pressure and decreased with the increasing consolidation confining pressure under the same initial dry density (Table 5). When the initial dry density was smaller, the permeability anisotropy was less pronounced and was less influenced by confining pressure. On the contrary, when the initial dry density was greater, the permeability anisotropy was more pronounced and confining pressure had a greater influence.

In order to examine the influence of the initial dry density on permeability anisotropy of saturated compacted loess, the relationship between the saturated permeability anisotropy ratio $r_{k s}$ (Table 5) and the initial dry density $\rho_{d}$ was linearly fitted according to the following equation: 
TABLE 3: Fitting parameters of the saturated permeability coefficient and initial dry density.

\begin{tabular}{|c|c|c|c|c|c|}
\hline \multirow{2}{*}{ Consolidation confining pressure $\sigma^{3}(\mathrm{kPa})$} & \multicolumn{5}{|c|}{ Fitting parameters } \\
\hline & Equation & $a$ & $b$ & $c$ & $R^{2}$ \\
\hline \multirow{2}{*}{100} & $k_{s h}=e^{-0.4455 \cdot \rho_{d}^{2}-1.3003 \cdot \rho_{d}-9.0284}$ & -0.4455 & -1.3003 & -9.0284 & 0.9605 \\
\hline & $k_{s v}=e^{-2.1050 \cdot \rho_{d}^{2}+2.4899 \cdot \rho_{d}-11.2385}$ & -2.1050 & 2.4899 & -11.2385 & 0.9452 \\
\hline \multirow{2}{*}{200} & $k_{s h}=e^{6.8075 \cdot \rho_{d}^{2}-24.6774 \cdot \rho_{d}+8.6995}$ & 6.8075 & -24.6774 & 8.6995 & 0.9646 \\
\hline & $k_{s v}=e^{9.9169 \cdot \rho_{d}^{2}-35.6333 \cdot \rho_{d}+17.8634}$ & 9.9169 & -35.6333 & 17.8634 & 0.9772 \\
\hline \multirow{2}{*}{300} & $k_{s h}=e^{-0.9346 \cdot \rho_{d}^{2}-0.2577 \cdot \rho_{d}-11.3574}$ & -0.9346 & -0.2577 & -11.3574 & 0.9999 \\
\hline & $k_{s v}=e^{0.3495 \cdot \rho_{d}^{2}-5.4986 \cdot \rho_{d}-6.5793}$ & 0.3495 & -5.4986 & -6.5793 & 0.9995 \\
\hline \multirow{2}{*}{400} & $k_{s h}=e^{2.7874 \cdot \rho_{d}^{2}-11.6690 \cdot \rho_{d}-3.4136}$ & 2.7874 & -11.6690 & -3.4136 & 0.9922 \\
\hline & $k_{s v}=e^{2.4810 \cdot \rho_{d}^{2}-11.8993 \cdot \rho_{d}-2.5098}$ & 2.4810 & -11.8993 & -2.5098 & 0.9924 \\
\hline
\end{tabular}

TABLE 4: Fitting parameters of the saturated permeability coefficient and consolidation confining pressure.

\begin{tabular}{|c|c|c|c|c|c|}
\hline \multirow{2}{*}{ Initial dry density $\rho_{d}\left(\mathrm{~g} / \mathrm{cm}^{3}\right)$} & \multicolumn{5}{|c|}{ Fitting parameters } \\
\hline & Equation & $a^{\prime}$ & $b^{\prime}$ & $c^{\prime}$ & $R^{2}$ \\
\hline \multirow[b]{2}{*}{1.70} & $k_{s h}=e^{-0.0000161 \cdot \sigma_{3}^{2}-0.0044 \cdot \sigma_{3}-11.9806}$ & -0.0000162 & -0.0044 & -11.9806 & 0.9945 \\
\hline & $k_{s v}=e^{-0.0000116 \cdot \sigma_{3}^{2}-0.0045 \cdot \sigma_{3}-12.6477}$ & -0.0000116 & -0.0045 & -12.6477 & 0.9940 \\
\hline \multirow{2}{*}{1.60} & $k_{s h}=e^{0.00000554 \cdot \sigma_{3}^{2}-0.0121 \cdot \sigma_{3}-11.0376}$ & 0.00000554 & -0.0121 & -11.0376 & 0.9999 \\
\hline & $k_{s v}=e^{-0.00000391 \cdot \sigma_{3}^{2}-0.0091 \cdot \sigma_{3}-11.5502}$ & -0.00000391 & -0.0091 & -11.550 & 20.9984 \\
\hline \multirow[b]{2}{*}{1.50} & $k_{s h}=e^{0.0000253 \sigma_{3}^{2}-0.0201 \cdot \sigma_{3}-10.2365}$ & 0.0000253 & -0.0201 & -10.2365 & 0.9995 \\
\hline & $k_{s v}=e^{0.0000229 \cdot \sigma_{3}^{2}-0.0187 \cdot \sigma_{3}-10.6291}$ & 0.0000229 & -0.0187 & -10.6291 & 0.9996 \\
\hline \multirow{2}{*}{1.40} & $k_{s h}=e^{0.0000467 \sigma_{3}^{2}-0.0299 \sigma_{3}-9.1241}$ & 0.0000467 & -0.0299 & -9.1241 & 0.9990 \\
\hline & $k_{s v}=e^{0.0000457 \cdot \sigma_{3}^{2}-0.0291 \cdot \sigma_{3}-9.3410}$ & 0.0000457 & -0.0291 & -9.3410 & 0.9986 \\
\hline
\end{tabular}

$$
r_{k s}=a^{\prime}+b^{\prime} \cdot \rho_{d}
$$

where $r_{k s}$ represents the saturated permeability anisotropy ratio; $a^{\prime}$ and $b^{\prime}$ represent linear fitting parameters (Table 6); and $\rho_{d}$ represents the initial dry density $\left(\mathrm{g} / \mathrm{cm}^{3}\right)$.

(1) Under the same consolidation confining pressure, the permeability anisotropy ratio increased with the increasing initial dry density, and the linear slope decreased with the increasing consolidation confining pressure (Figure 8 ). When the initial dry density was near the maximum dry density $\left(1.73 \mathrm{~g} / \mathrm{cm}^{3}\right)$, the permeability anisotropy ratio was the largest. Under the same initial dry density, the permeability anisotropy ratio decreased with the increasing consolidation confining pressure. The permeability anisotropy ratio was relatively small at high consolidation confining pressure $\left(\sigma_{3}=400 \mathrm{kPa}\right)$.

(2) During compaction, compaction energy eventually transformed into potential energy within soil particles, self-inversion, and mutual imbedding. The flake-, needle-, and plate-like particles were constantly adjusted to be nearly perpendicular to the compaction direction, which led to low pore connectivity in the direction perpendicular to the compaction plane, resulting in obvious differences between the pore structure parallel and perpendicular to the compaction plane. Under the same hydraulic gradient, the circuitous path of water seepage in the direction perpendicular to the compaction surface was longer than that parallel to the compaction surface. Thus, the permeability coefficient perpendicular to the compaction surface was smaller than the permeability coefficient parallel to the compaction surface. The circuitous path was greatly affected by the soil initial dry density and consolidation confining pressure.

(3) When $\sigma_{c}=0 \mathrm{kPa}$ and $\rho_{d}=1.70 \mathrm{~g} / \mathrm{cm}^{3}$, the ratio of the horizontal permeability coefficient to the vertical permeability coefficient was the largest, reaching 1.951. When the soil initial dry density was larger, small pores were the main type and the orientation of particles was more remarkable. The main contact types between particles were surface-to-surface and line-to-surface. The permeability of compacted loess decreased significantly, and although the permeability coefficient was minimized, the ratio of the horizontal to the vertical permeability coefficient was maximized. On the contrary, when the initial dry density of soil was small, primarily large pores were present and the particles did not have a uniform orientation. The main contact types between particles were primarily point-to-surface and line-tosurface. The permeability coefficient was large, and the ratio of the horizontal to the vertical permeability coefficient was small.

(4) During consolidation of compacted loess under a confining pressure, the orientation of soil particles became more and more disordered, which led to a decrease in horizontal and vertical permeability anisotropy. The ratio of permeability anisotropy decreased with the increasing confining pressure. 


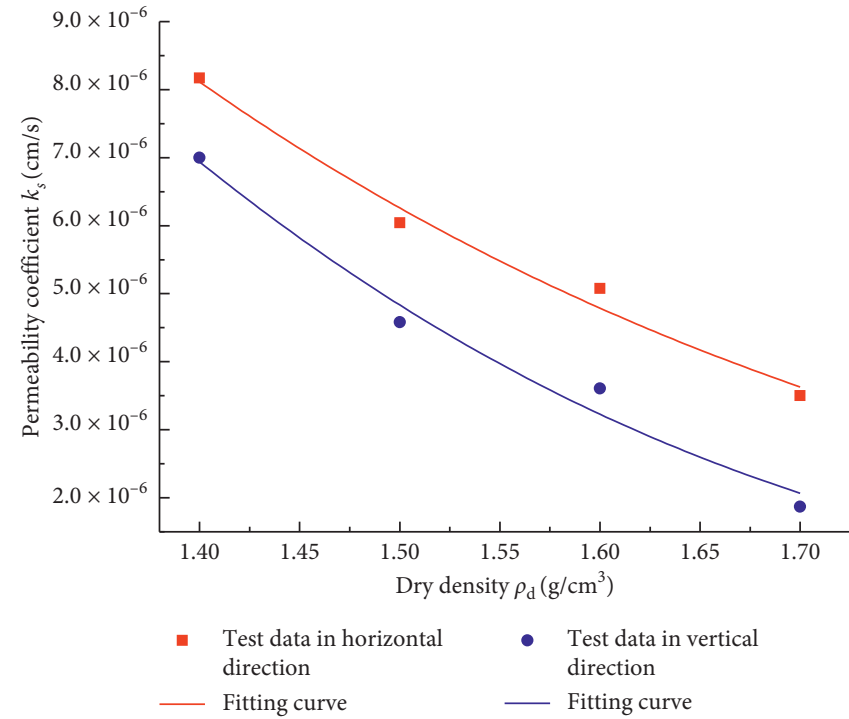

(a)

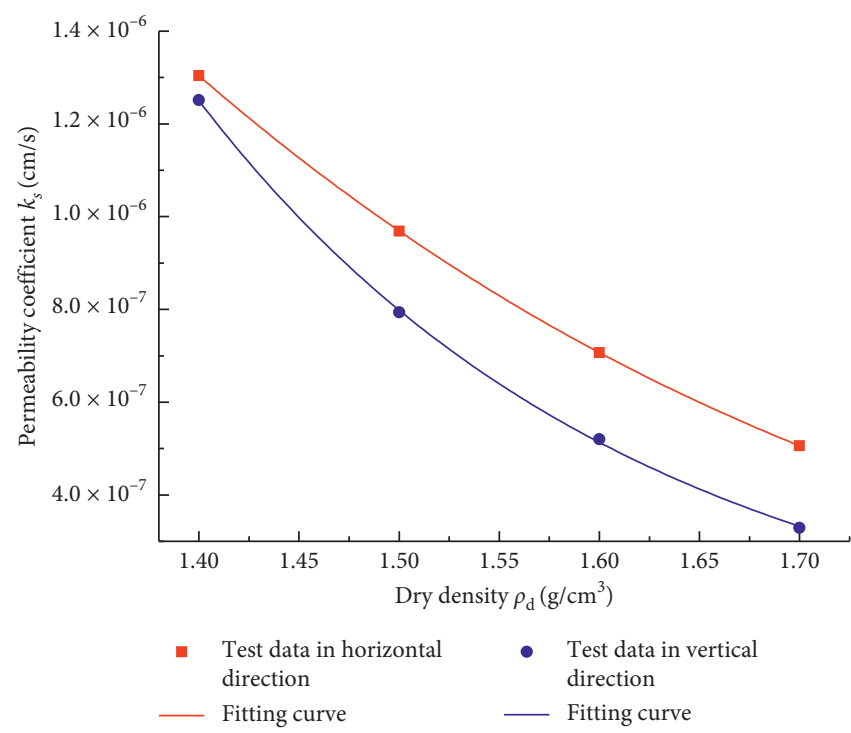

(c)

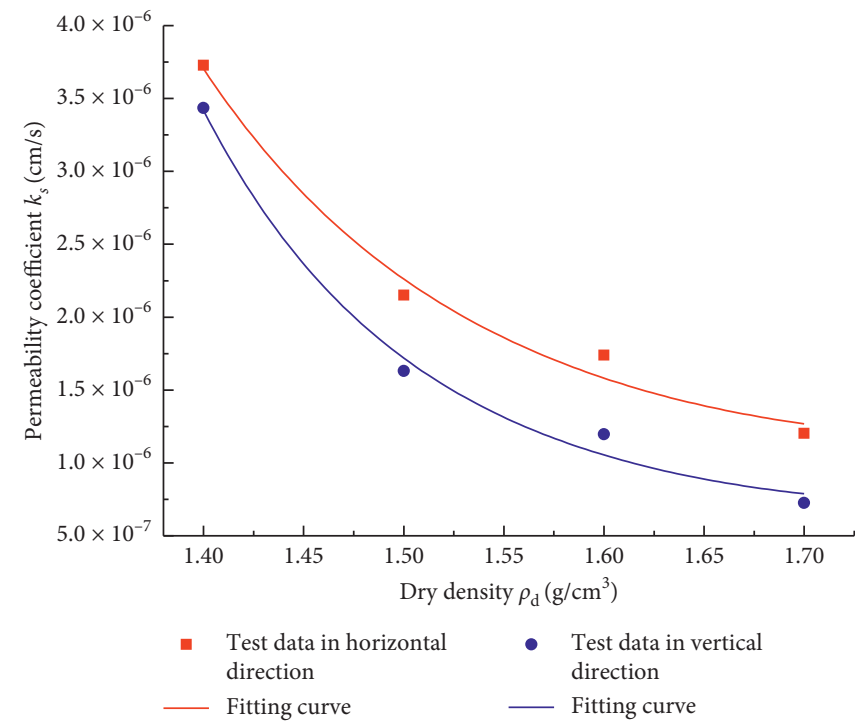

(b)

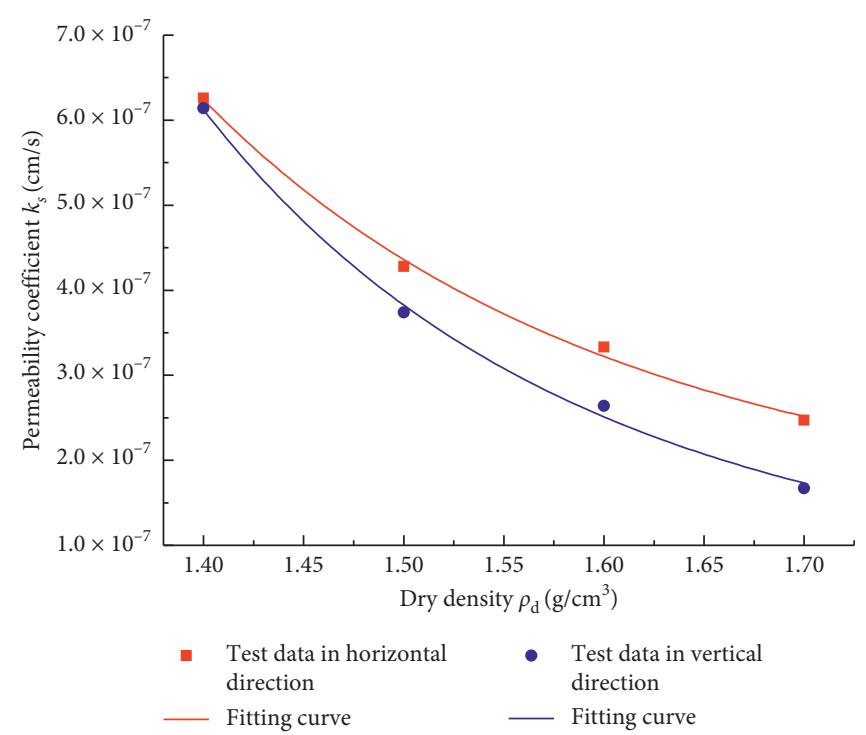

(d)

FIGURE 6: Relationship between the saturated permeability coefficient and the initial dry density under confining pressure consolidation. (a) $\sigma_{3}=100 \mathrm{kPa}$. (b) $\sigma_{3}=200 \mathrm{kPa}$. (c) $\sigma_{3}=300 \mathrm{kPa}$. (d) $\sigma_{3}=400 \mathrm{kPa}$.

3.2. Saturated Permeability of Compacted Loess under $K_{0}$ Consolidation. The value of $K_{0}$ tended to be constant with the increasing lateral stress and axial stress during the consolidation of $K_{0}$. $K_{0}$ consolidation tests were carried out on soil samples with the initial dry density of $1.40 \mathrm{~g} / \mathrm{cm}^{3}$, $1.50 \mathrm{~g} / \mathrm{cm}^{3}, 1.60 \mathrm{~g} / \mathrm{cm}^{3}$, and $1.70 \mathrm{~g} / \mathrm{cm}^{3}$. The average value of $K_{0}$ corresponding to each initial dry density was taken, and the curve between $K_{0}$ and dry density was established, as shown in Figure 9.

$K_{0}$ was obviously affected by the initial dry density. With the increasing dry density, the value of $K_{0}$ decreased gradually. The relationship between $K_{0}$ and the initial dry density was approximately linear (Figure 9).
The triaxial permeability test results of vertical and horizontal specimens of compacted loess consolidated by $K_{0}$ are shown in Table 7.

The saturated permeability coefficient of compacted loess decreased with the increasing initial dry density under $K_{0}$ consolidation (Table 7). Compacted loess at different depths was in the $K_{0}$ state after filling works were completed. $K_{0}$ consolidation evolved macropores to uniform small pores, and the flake- and needle-like particles continuously rotated parallel to the compaction surface. Particle orientation enhanced the connectivity of vertical pores, which eventually led to the horizontal permeability coefficient of compacted loess significantly larger than the vertical permeability coefficient. 


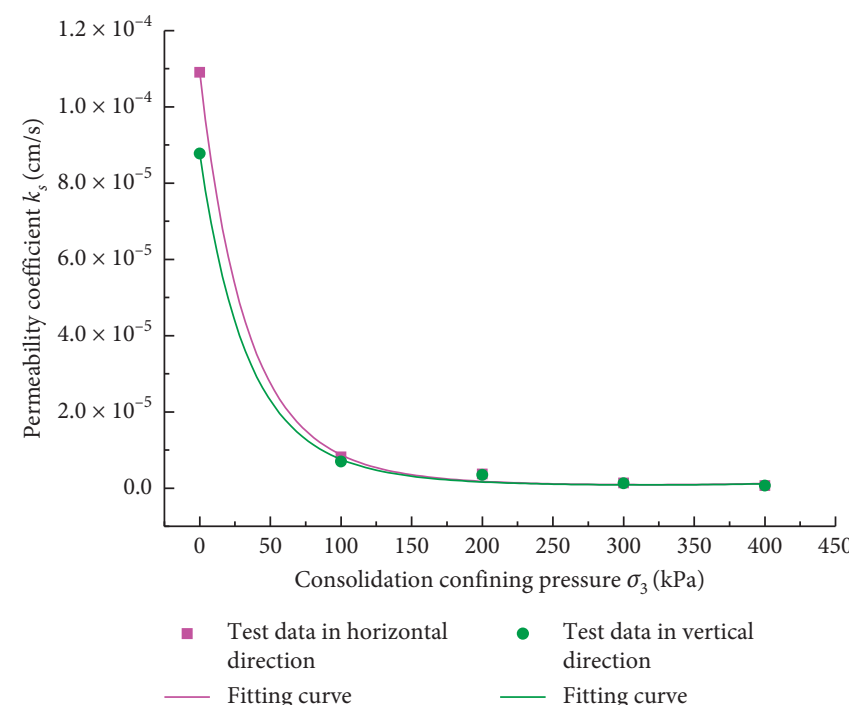

(a)

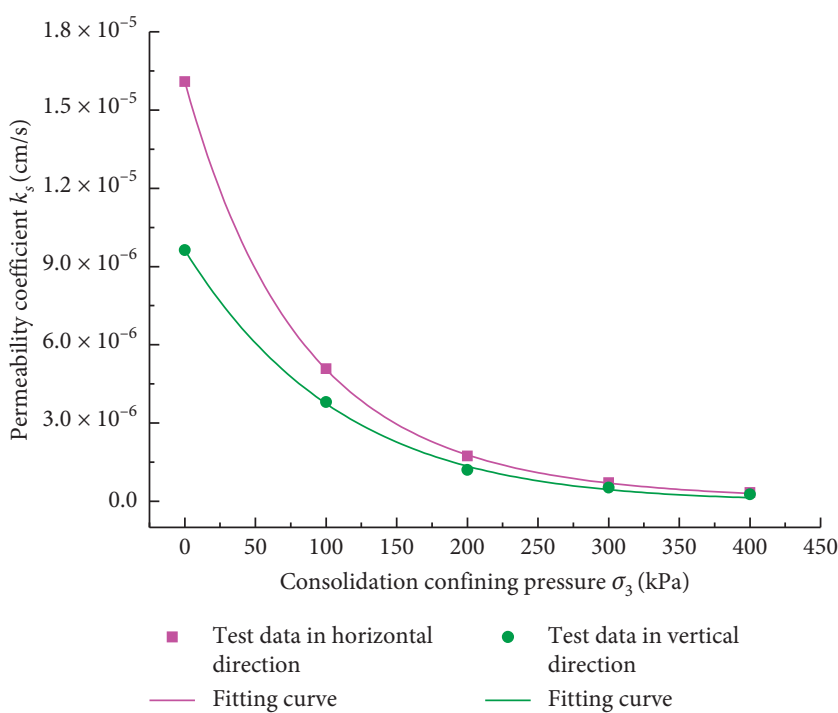

(c)

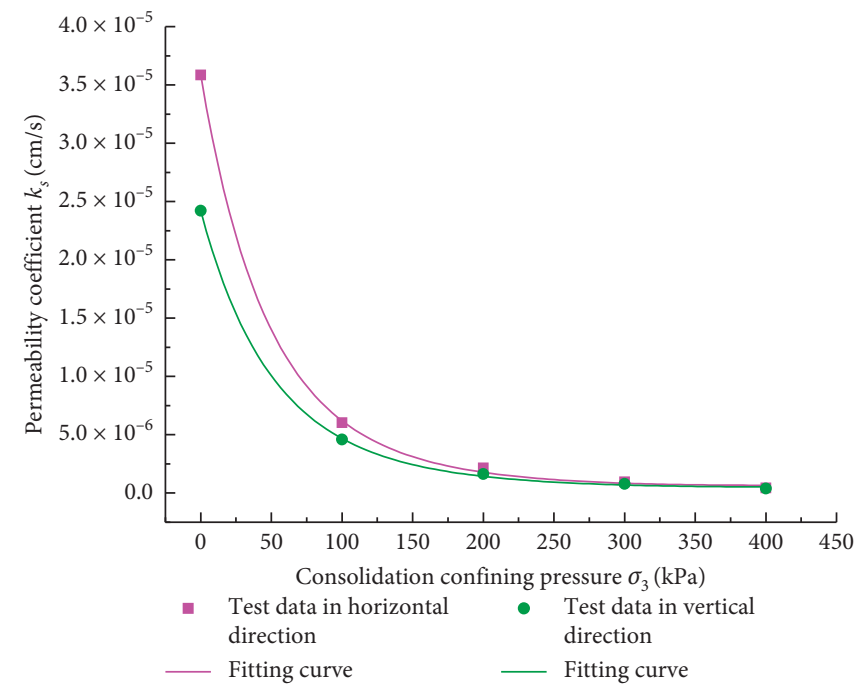

(b)

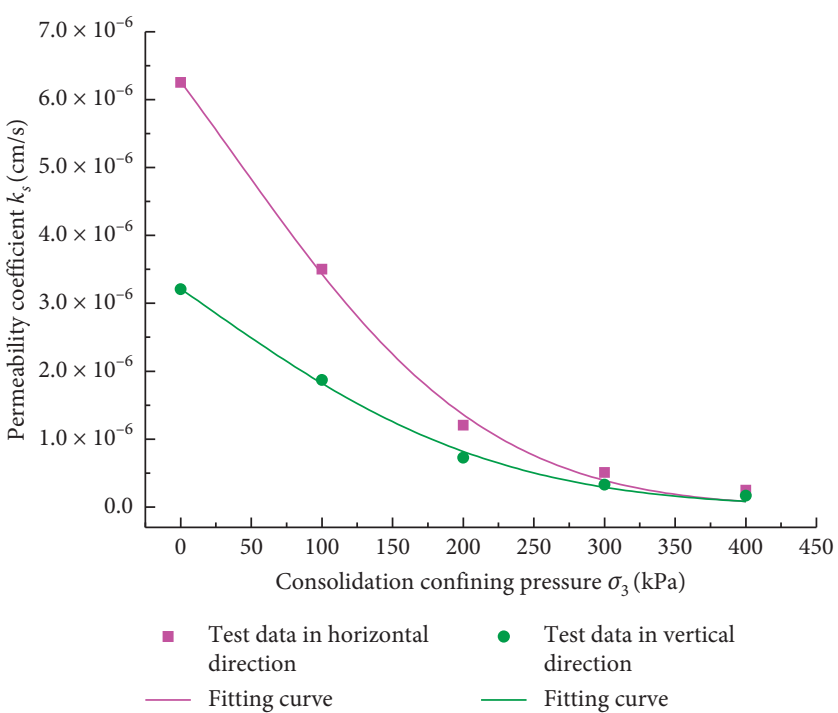

(d)

FIGURE 7: Relationship between the saturated permeability coefficient and the consolidation confining pressure. (a) Initial dry density $\rho_{d}=1.40 \mathrm{~g} / \mathrm{cm}^{3}$. (b) Initial dry density $\rho_{d}=1.50 \mathrm{~g} / \mathrm{cm}^{3}$. (c) Initial dry density $\rho_{d}=1.60 \mathrm{~g} / \mathrm{cm}^{3}$. (d) Initial dry density $\rho_{d}=1.70 \mathrm{~g} / \mathrm{cm}^{3}$.

TABle 5: Permeability anisotropy ratio of saturated compacted loess under confining pressure consolidation.

\begin{tabular}{lcccc}
\hline Initial dry density $\rho_{d}$ & \multicolumn{4}{c}{ Permeability anisotropy ratio $r_{k s}$} \\
$\left(\mathrm{~g} / \mathrm{cm}^{3}\right)$ & $100 \mathrm{kPa}$ & $200 \mathrm{kPa}$ & $300 \mathrm{kPa}$ & $400 \mathrm{kPa}$ \\
\hline 1.70 & 1.871 & 1.657 & 1.538 & 1.484 \\
1.60 & 1.569 & 1.453 & 1.359 & 1.263 \\
1.50 & 1.398 & 1.318 & 1.220 & 1.146 \\
1.40 & 1.168 & 1.085 & 1.043 & 1.021 \\
\hline
\end{tabular}

The saturated permeability coefficient (Table 7) of compacted loess under the $K_{0}$ consolidation condition was analyzed by nonlinear regression according to equation (1). Fitting parameters are shown in Table 8 , and the fitting curves are shown in Figure 10.
The relationship between the saturated permeability coefficient and the dry density of compacted loess under the $K_{0}$ consolidation condition was still an exponential function (Table 8) (Figure 10). According to the fitting equation (Table 8), the saturated permeability coefficients of compacted loess with different dry densities and different depths could be estimated, providing a basis for the analysis of the water field in loess filling engineering. Under the condition of $K_{0}$ consolidation, the void ratio of soil was further reduced, the connectivity of voids became worse, and the permeability coefficient of soil decreased. The change rule of the saturated permeability coefficient of compacted loess under $K_{0}$ consolidation was similar to that under confining pressure consolidation.

The permeability coefficients (Table 7) of saturated compacted loess were calculated by formula (3), and the 
TABLE 6: Linear fitting parameters under confining pressure consolidation.

\begin{tabular}{lccc}
\hline Consolidation confining pressure $\sigma_{3}(\mathrm{kPa})$ & \multicolumn{3}{c}{ Fitting parameters } \\
& $a^{\prime}$ & $b^{\prime}$ & Equation \\
\hline 100 & -2.0325 & 2.280 & $R_{k s}=-2.0325+2.280 \rho_{d}$ \\
200 & -1.4908 & 1.851 & $r_{k s}=-1.4908+1.851 \rho_{d}$ \\
300 & -1.2272 & 1.624 & $r_{k s}=-1.2272+1.624 \rho_{d}$ \\
400 & -1.1058 & 1.506 & $r_{k s}=-1.1058+1.506 \rho_{d}$ \\
\hline
\end{tabular}

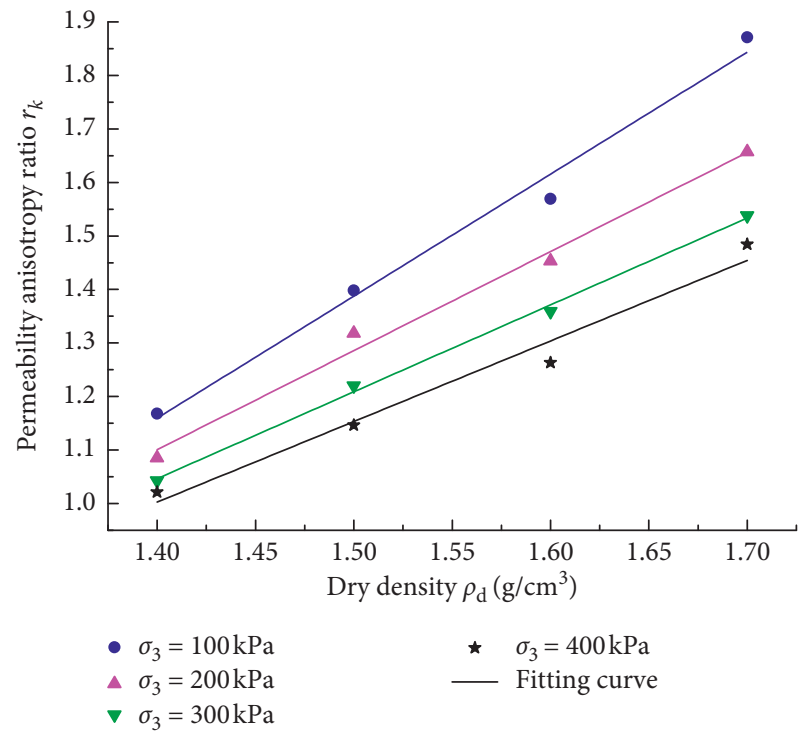

FIGURE 8: Relationship between the permeability anisotropy ratio and the initial dry density under confining pressure consolidation.

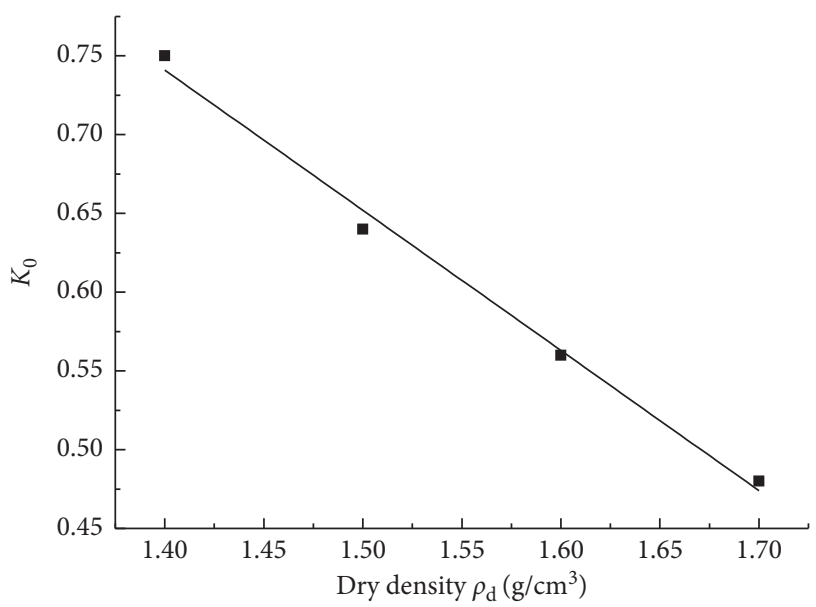

- $K_{0}$ test data

Fitting equation $K_{0}=1.987-0.89 \cdot \rho_{\mathrm{d}}, R^{2}=0.990$

Figure 9: Relationship between the $K_{0}$ coefficient and the initial dry density.

permeability anisotropy ratios are shown in Table 9. The relationship between the saturated permeability anisotropy ratio $r_{k s}$ (Table 9) under $K_{0}$ consolidation and the initial dry
TABLe 7: Permeability coefficient of saturated compacted loess under $K_{0}$ consolidation.

\begin{tabular}{lccccccccc}
\hline Initial dry & \multicolumn{9}{c}{ Saturated permeability coefficient $k_{s}\left(10^{-6} \mathrm{~cm} / \mathrm{s}\right)$} \\
density & \multicolumn{3}{c}{$100 \mathrm{kPa}$} & \multicolumn{2}{c}{$200 \mathrm{kPa}$} & \multicolumn{2}{c}{$300 \mathrm{kPa}$} & \multicolumn{2}{c}{$400 \mathrm{kPa}$} \\
$\rho_{d}\left(\mathrm{~g} / \mathrm{cm}^{3}\right)$ & $k_{s h}$ & $k_{s v}$ & $k_{s h}$ & $k_{s v}$ & $k_{s h}$ & $k_{s v}$ & $k_{s h}$ & $k_{s v}$ \\
\hline 1.70 & 2.980 & 1.516 & 0.932 & 0.520 & 0.359 & 0.219 & 0.161 & 0.104 \\
1.60 & 4.026 & 2.478 & 1.210 & 0.799 & 0.436 & 0.316 & 0.189 & 0.146 \\
1.50 & 4.449 & 2.954 & 1.402 & 1.038 & 0.595 & 0.477 & 0.258 & 0.214 \\
1.40 & 5.684 & 4.534 & 2.518 & 2.113 & 0.814 & 0.727 & 0.365 & 0.337 \\
\hline
\end{tabular}

density $\rho_{d}$ was linearly fitted according to equation (4). Fitting parameters are shown in Table 10, and the fitting curves are shown in Figure 11.

The saturated permeability anisotropy ratio of compacted loess increased with the increasing dry density under the $K_{0}$ consolidation condition. The anisotropy ratio of saturated permeability was linear with the initial dry density (Figure 11). The change rule of the saturated permeability anisotropy ratio of compacted loess under $K_{0}$ consolidation was similar to that under confining pressure consolidation.

The linear equation of $K_{0}$ and dry density fitted in Figure 9 was substituted into equations (1) and (4) to obtain the following equations, respectively:

$$
\begin{aligned}
& k_{s}=e^{a \cdot\left(2.1315-1.1236 K_{0}\right)^{2}+b \cdot\left(2.1315-1.1236 K_{0}\right)+c}, \\
& r_{k s}=a^{\prime}+b^{\prime} \cdot\left(2.1315-1.1236 K_{0}\right),
\end{aligned}
$$

where $k_{s}$ represents the saturated permeability coefficient, $\mathrm{cm} / \mathrm{s} ; r_{k s}$ represents the saturated permeability anisotropic ratio; $K_{0}$ represents the coefficient of earth pressure at rest; and $a, b, c, d, a^{\prime}$, and $b^{\prime}$ represent fitting parameters.

With the decreasing $K_{0}$ value, the saturated permeability coefficient and permeability anisotropy of compacted loess increased gradually. In compacted loess engineering, the saturated permeability coefficient and anisotropic ratio of compacted loess could be calculated according to equations (5) and (6) by the value of $K_{0}$ and the experimental fitting parameters $a, b, c, a^{\prime}$, and $\mathrm{b}^{\prime}$, which had certain application value in analysing the distribution of the water field of compacted loess.

3.3. Comparative Analysis of Permeability Characteristics of Compacted Loess under Confining Pressure Consolidation and $K_{0}$ Consolidation. The saturated permeability of compacted loess under $K_{0}$ consolidation and confining pressure 
TABLe 8: Fitting parameters under $K_{0}$ consolidation.

\begin{tabular}{|c|c|c|c|c|c|}
\hline \multirow{2}{*}{ Consolidation confining pressure $\sigma^{3}(\mathrm{kPa})$} & \multicolumn{5}{|c|}{ Fitting parameters } \\
\hline & Equation & $a$ & $b$ & $c$ & $R^{2}$ \\
\hline \multirow[b]{2}{*}{100} & $k_{s h}=e^{0.3301 \cdot \rho_{d}^{2}-3.0165 \cdot \rho_{d}+5.3029}$ & 0.3301 & -3.0165 & 5.3029 & 0.884 \\
\hline & $k_{s v}=e^{1.1713 \cdot \rho_{d}^{2}-7.0138 \cdot \rho_{d}+9.0261}$ & 1.1713 & -7.0138 & 9.0261 & 0.933 \\
\hline \multirow[b]{2}{*}{200} & $k_{s h}=e^{10.1579 \cdot \rho_{d}^{2}-34.6249 \cdot \rho_{d}+29.4816}$ & 10.1579 & -34.6249 & 29.4816 & 0.949 \\
\hline & $k_{s v}=e^{10.3482 \cdot \rho_{d}^{2}-36.4984 \cdot \rho_{d}+31.5583}$ & 10.3482 & -36.4984 & 31.5583 & 0.971 \\
\hline \multirow{2}{*}{300} & $k_{s h}^{s v}=e^{2.5188 \cdot \rho_{d}^{2}-10.5811 \cdot \rho_{d}+9.6730}$ & 2.5188 & -10.5811 & 9.6730 & 0.996 \\
\hline & $k_{s v}=e^{1.1606 \cdot \rho_{d}^{2}-7.6152 \cdot \rho_{d}+8.0681}$ & 1.1606 & -7.6152 & 8.0681 & 0.999 \\
\hline \multirow[b]{2}{*}{400} & $k_{s h}=e^{4.2149 \cdot \rho_{d}^{2}-15.8362 \cdot \rho_{d}+12.9037}$ & 4.2149 & -15.8362 & 12.9037 & 0.996 \\
\hline & $k_{s y}=e^{3.0295 \cdot \rho_{d}^{2}-13.2970 \cdot \rho_{d}+11.5901}$ & 3.0295 & -13.2970 & 11.5901 & 0.999 \\
\hline
\end{tabular}

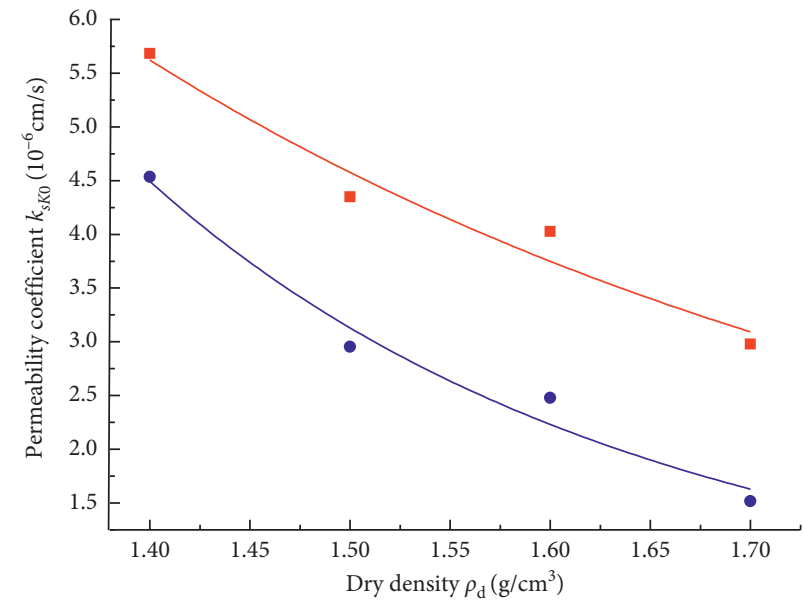

- Test data in horizontal direction

__ Fitting curve

- Test data in vertical direction

__ Fitting curve

(a)

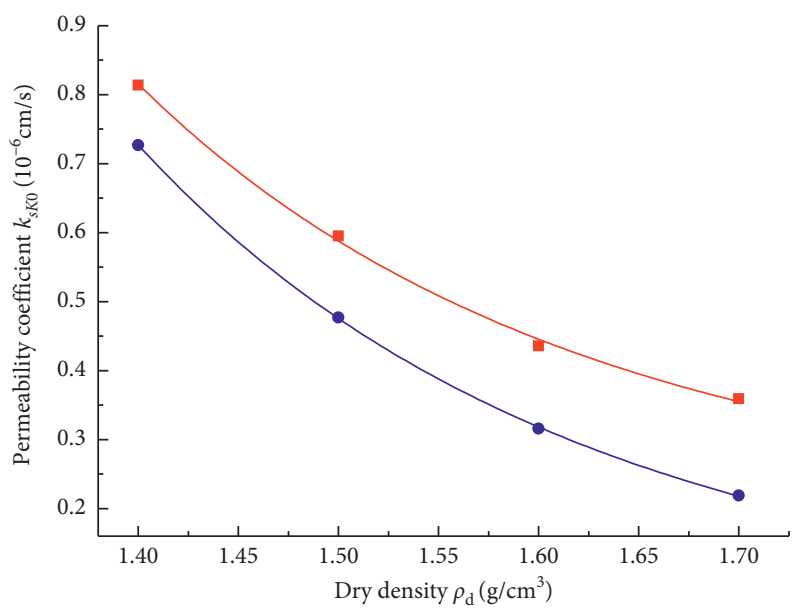

- Test data in horizontal direction

__ Fitting curve

- Test data in vertical direction

__ Fitting curve

(c)

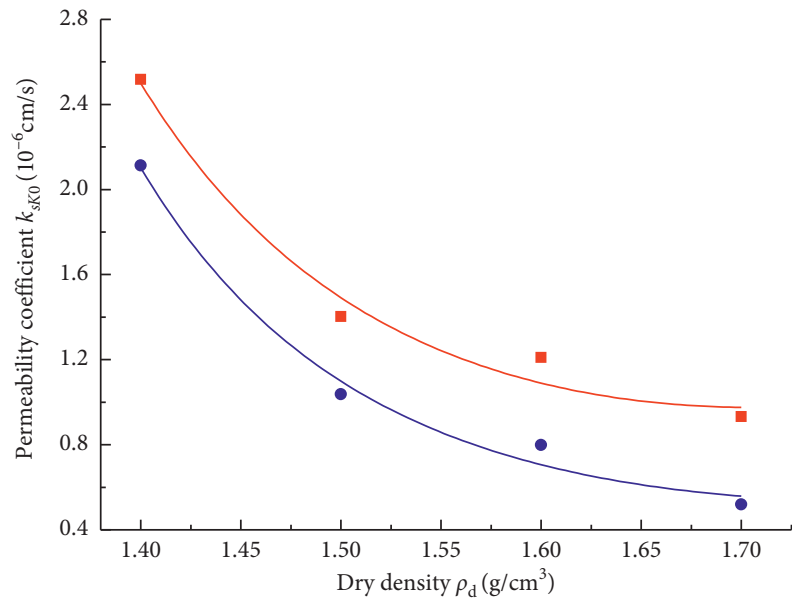

- Test data in horizontal direction

- Test data in vertical direction

_ Fitting curve

__ Fitting curve

(b)

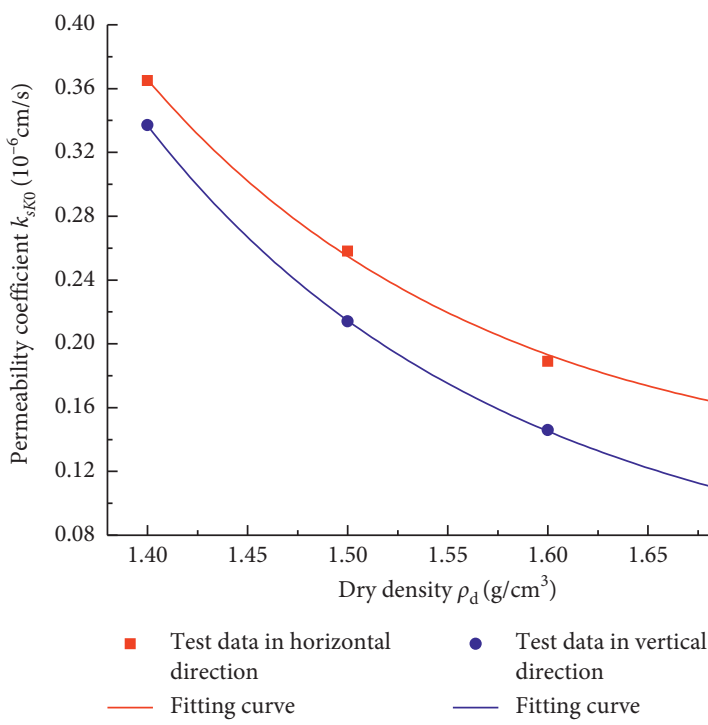

(d)

FIGURE 10: Relationship between the saturated permeability coefficient and the dry density under $K_{0}$ consolidation. (a) $\sigma_{3}=100 \mathrm{kPa}$. (b) $\sigma_{3}=200 \mathrm{kPa}$. (c) $\sigma_{3}=300 \mathrm{kPa}$. (d) $\sigma_{3}=400 \mathrm{kPa}$. 
TABle 9: Permeability anisotropy ratio of saturated compacted loess under $K_{0}$ consolidation.

\begin{tabular}{lcccc}
\hline \multirow{2}{*}{$\begin{array}{l}\text { Initial dry density } \rho_{d} \\
\left(\mathrm{~g} / \mathrm{cm}^{3}\right)\end{array}$} & \multicolumn{4}{c}{ Permeability anisotropy ratio $r_{k s}$} \\
& $100 \mathrm{kPa}$ & $200 \mathrm{kPa}$ & $300 \mathrm{kPa}$ & $400 \mathrm{kPa}$ \\
\hline 1.70 & 1.965 & 1.793 & 1.640 & 1.548 \\
1.60 & 1.625 & 1.515 & 1.376 & 1.295 \\
1.50 & 1.472 & 1.350 & 1.248 & 1.206 \\
1.40 & 1.254 & 1.192 & 1.119 & 1.085 \\
\hline
\end{tabular}

TABLE 10: Linear fitting parameters under $K_{0}$ consolidation.

\begin{tabular}{lcccc}
\hline $\begin{array}{l}\text { Consolidation } \\
\text { confining } \\
\text { pressure } \sigma_{3}(\mathrm{kPa})\end{array}$ & $a^{\prime}$ & $b^{\prime}$ & Equation & $R^{2}$ \\
\hline 100 & -1.9658 & 2.287 & $r_{k s}=-1.9658+2.287 \rho_{d}$ & 0.961 \\
200 & -1.5909 & 1.970 & $r_{k s}=-1.5909+1.970 \rho_{d}$ & 0.969 \\
300 & -1.2767 & 1.692 & $r_{k s}=-1.2767+1.692 \rho_{d}$ & 0.945 \\
400 & -1.0096 & 1.479 & $r_{k s}=-1.0096+1.479 \rho_{d}$ & 0.918 \\
\hline
\end{tabular}

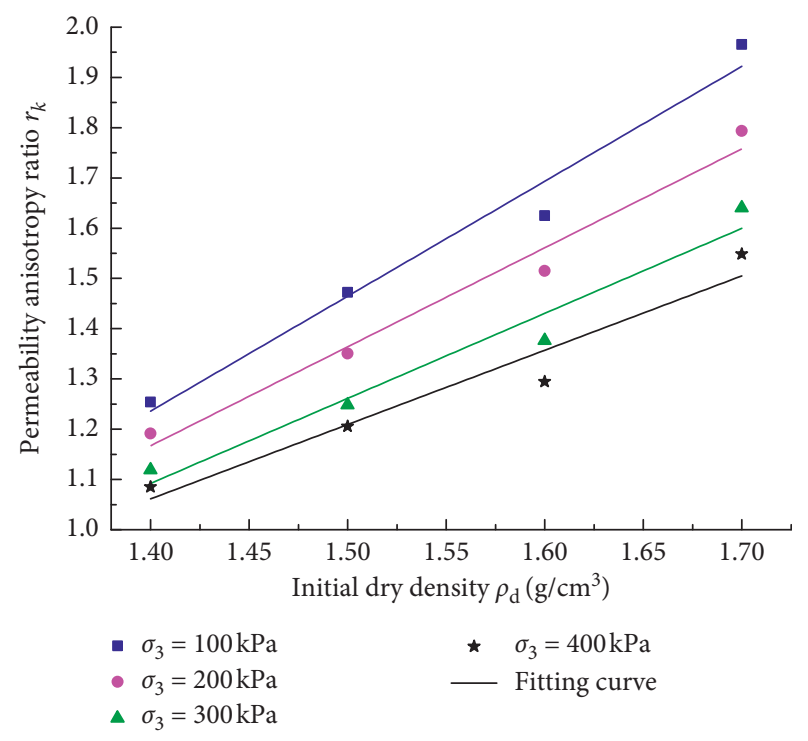

FIGURE 11: Relationship between the permeability anisotropy ratio and the initial dry density under $K_{0}$ consolidation.

consolidation was obviously different. The saturated permeability coefficient of compacted loess under $K_{0}$ consolidation was smaller than that under confining consolidation. With the increasing initial dry density, the saturated permeability coefficient and the saturated permeability anisotropy ratio increased gradually. In order to quantitatively describe and analyze the saturated permeability difference of compacted loess under $K_{0}$ consolidation and confining pressure consolidation, the permeability coefficient ratio $R_{k}$ was defined (equation (7)). When $R_{k}<1$, the permeability coefficient of compacted loess under $K_{0}$ consolidation was less than that under confining pressure consolidation, and when $R_{k} \approx 1$, the permeability coefficient was approximately equal.
The saturated permeability test data in Tables 2 and 7 were calculated according to equation (7). The results are shown in Figure 12.

$$
R_{k}=\frac{k_{K_{0}}}{k_{\sigma_{c}}}
$$

where $R_{k}$ represents the saturated permeability coefficient ratio of compacted loess under $K_{0}$ consolidation and confining pressure consolidation; $k_{K_{0}}$ represents the saturated permeability coefficient under $K_{0}$ consolidation, $\mathrm{cm} / \mathrm{s}$; and $k_{\sigma_{c}}$ represents the saturated permeability coefficient under confining pressure consolidation, $\mathrm{cm} / \mathrm{s}$.

The saturated permeability coefficient ratio of vertical and horizontal compacted loess was between 0.5 and 0.9 , which indicated that the saturated permeability coefficient of compacted loess under $K_{0}$ consolidation decreased in both vertical and horizontal directions compared with that under confining pressure consolidation (Figure 12). The ratio of the horizontal permeability coefficient in the same dry density was smaller than that in the vertical direction, which was due to the decrease of vertical and horizontal void ratios caused by $K_{0}$ consolidation, the weakening of connectivity pores, and the enhancement of tortuosity, which had a greater impact in the horizontal direction. With the increasing confining pressure, the saturated permeability coefficient ratio of vertical and horizontal compacted loess decreased gradually. The saturated permeability coefficient ratio of compacted loess decreased with the decreasing dry density. $K_{0}$ consolidation reduced the void ratio of soil samples with a small dry density by a large margin.

In order to analyze the relationship between the saturated permeability coefficient ratio and $K_{0}$ of compacted loess, the relationship curves were established by Figures 9 and 12 and equation (7). The curves are shown in Figure 13.

The saturated permeability coefficient ratio $R_{\mathrm{k}}$ was obviously affected by the $K_{0}$ coefficient. The saturated permeability coefficient ratio decreased with the increasing $K_{0}$ (Figure 13). When the confining pressure was smaller, the saturated permeability coefficient ratio was larger and the curve was located at the top of Figure 13. The curve gradually moved down with the increasing confining pressure. The $R_{k}-K_{0}$ curve further proved that the permeability coefficient measured by the triaxial permeability test under the condition of constant confining pressure was larger than that measured by the triaxial permeability test under the condition of $K_{0}$ consolidation which was close to the in situ stress state of soil, and when $\rho_{d}=1.7 \mathrm{~g} / \mathrm{cm}^{3}$, the deviation even reached about $20 \%$. Therefore, it was recommended to adopt the triaxial permeability test under the $K_{0}$ consolidation condition to reduce the error of the saturated permeability coefficient caused by the triaxial permeability test under the condition of constant confining pressure. When studying the permeability of compacted loess, the permeability coefficient under the $K_{0}$ consolidation condition could also be obtained by modifying the permeability coefficient with the $R_{\mathrm{k}}$ value provided in Figure 13 under the condition of constant confining pressure consolidation. 


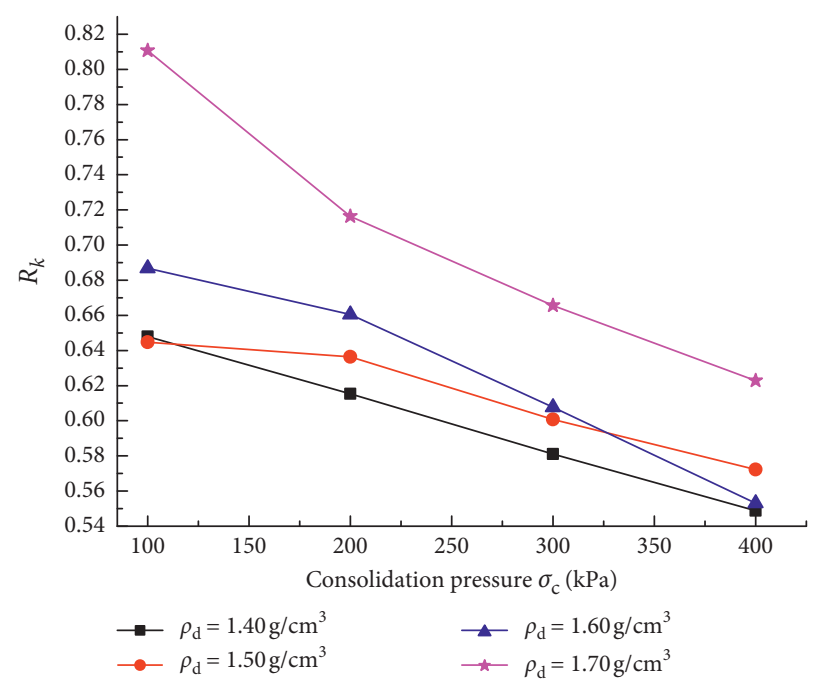

(a)

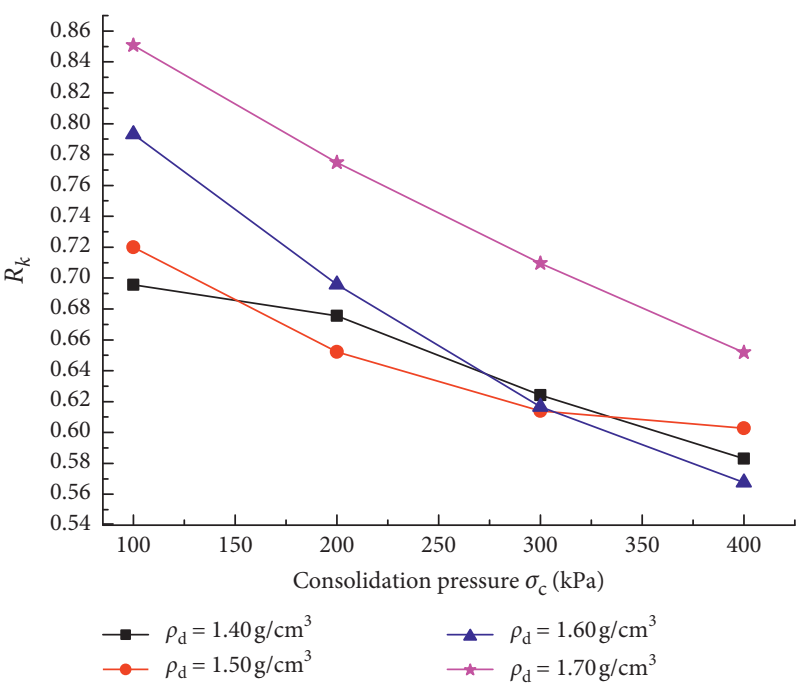

(b)

FiguRE 12: Saturated permeability ratio of compacted loess under $K_{0}$ consolidation and confining pressure consolidation. (a) $R_{k}$ in the horizontal direction. (b) $R_{k}$ in the vertical direction.

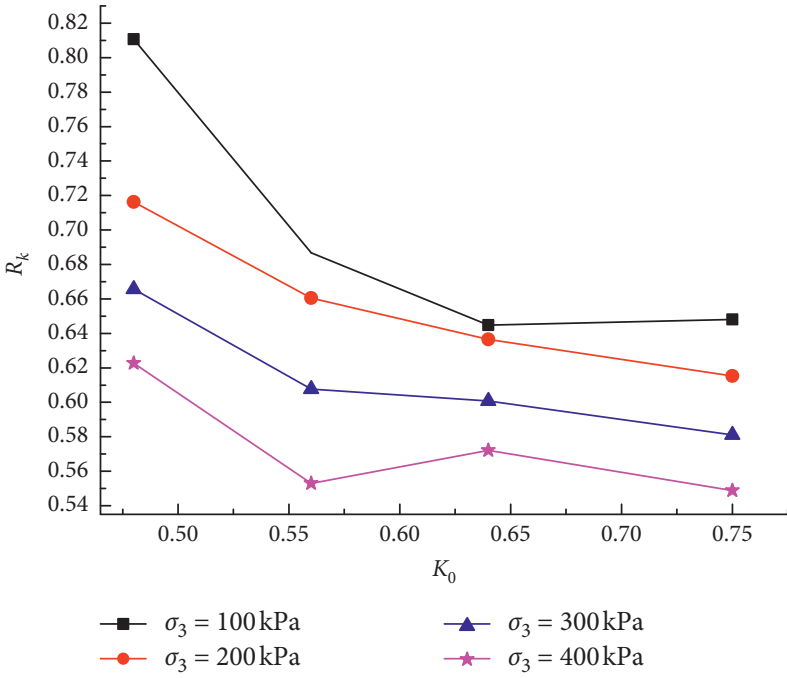

(a)

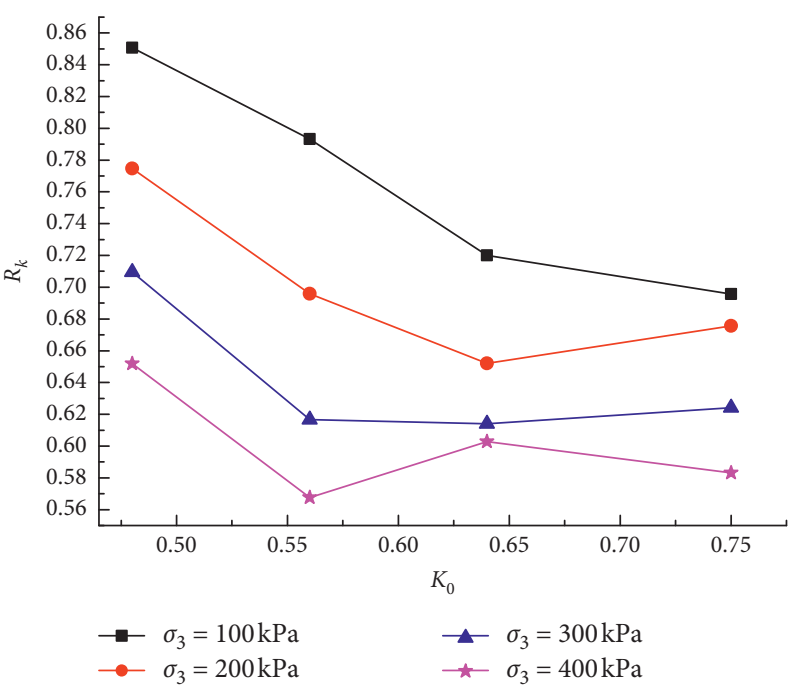

(b)

FiguRE 13: Relationship curves between the saturated permeability ratio $R_{k}$ and $K_{0}$. (a) $R_{k}$ in the horizontal direction. (b) $R_{k}$ in the vertical direction.

In order to analyze the difference of saturated permeability anisotropy between compacted loess under $K_{0}$ consolidation and confining pressure consolidation, the relationship between the saturated permeability anisotropy ratio and the confining pressure is drawn in Figure 14.

The saturated permeability anisotropy ratio of compacted loess increased significantly under $K_{0}$ consolidation, which indicated that $K_{0}$ consolidation made the flake- and needle-like particles in compacted loess rotate continuously parallel to the compaction plane, which enhanced the orientation of particles and ultimately led to the increase of saturated permeability anisotropy of compacted loess (Figure 14).

\section{Microscopic Mechanism of Permeability Anisotropy of Compacted Loess}

The macroporous structure of undisturbed loess is commonly destroyed by vertical rolling or tamping. Pores changed from macropores to medium and small pores. The soil particles take on a preferred orientation when under vertical load. Pore structures and particle arrangements determine the permeability characteristics of compacted loess. In order to reveal the permeability anisotropy of compacted loess, SEM tests were carried out on loess samples with different compacted dry densities to obtain images of the compacted surface and region perpendicular to the compacted surface (Figure 15). 


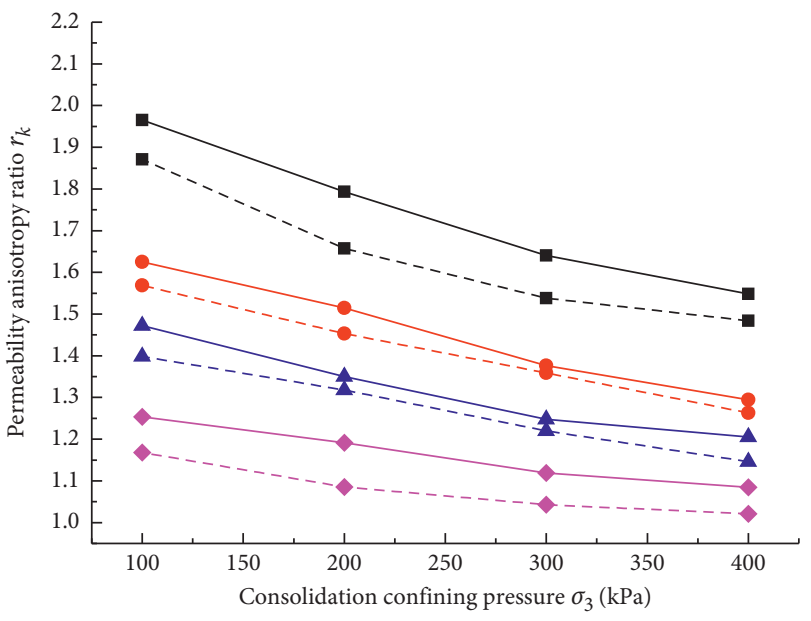

\begin{tabular}{|c|c|c|}
\hline$K_{0}$ consolidation & Confining & ssure consolidati \\
\hline$\rightarrow-$ & $-\mathbf{m -}$ & $\rho_{\mathrm{d}}=1.70 \mathrm{~g} / \mathrm{cm}^{3}$ \\
\hline$\bullet-$ & $-\bullet$ & $\rho_{\mathrm{d}}=1.60 \mathrm{~g} / \mathrm{cm}^{3}$ \\
\hline- & $-\mathbf{\Delta -}$ & $\rho_{\mathrm{d}}=1.50 \mathrm{~g} / \mathrm{cm}^{3}$ \\
\hline 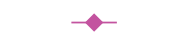 & - & $\rho_{\mathrm{d}}=1.40 \mathrm{~g} / \mathrm{cm}^{3}$ \\
\hline
\end{tabular}

FiguRE 14: Saturated permeability anisotropy ratio of compacted loess under $K_{0}$ consolidation and confining pressure consolidation.

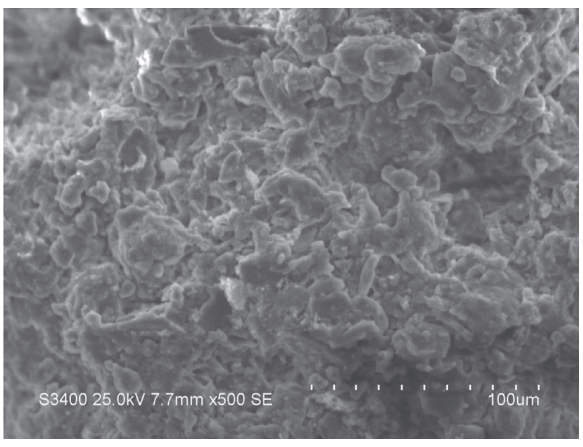

SEM image on compacted surface

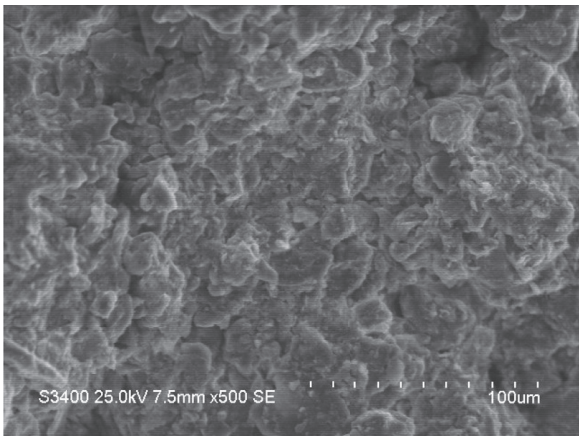

SEM image on compacted surface

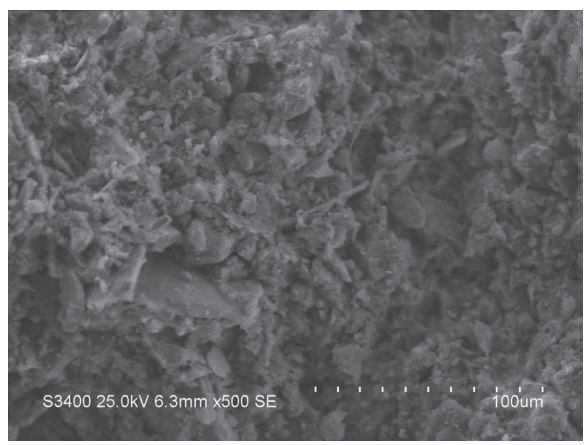

SEM image on vertical compacted surface

(a)

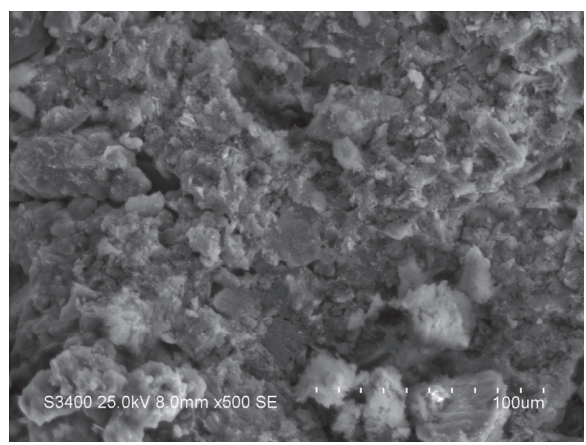

SEM image on vertical compacted surface

(b)

FIgURE 15: Continued. 


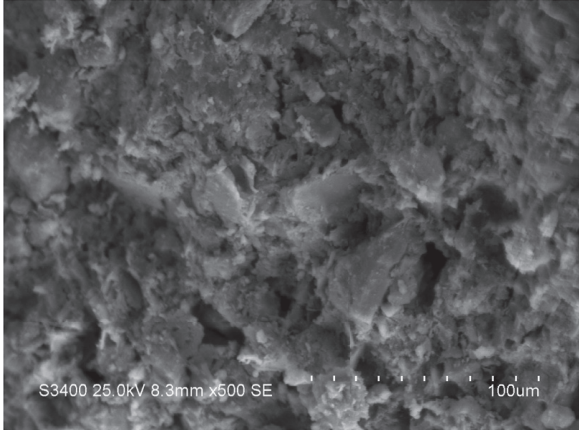

SEM image on compacted surface

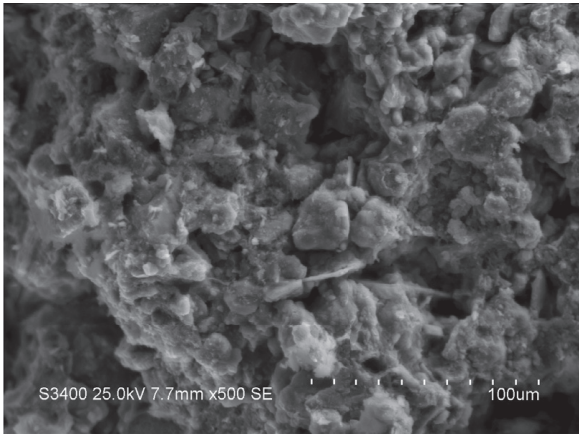

SEM image on compacted surface

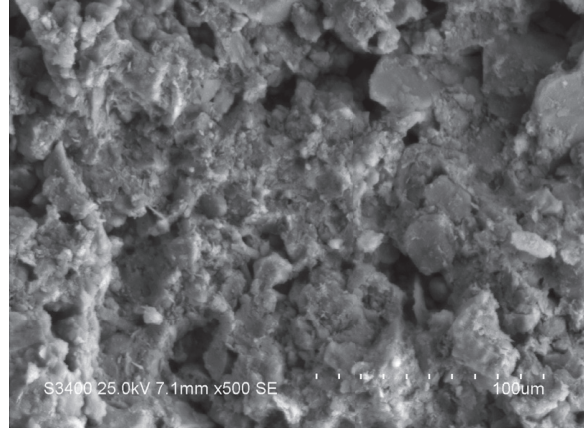

SEM image on vertical compacted surface

(c)

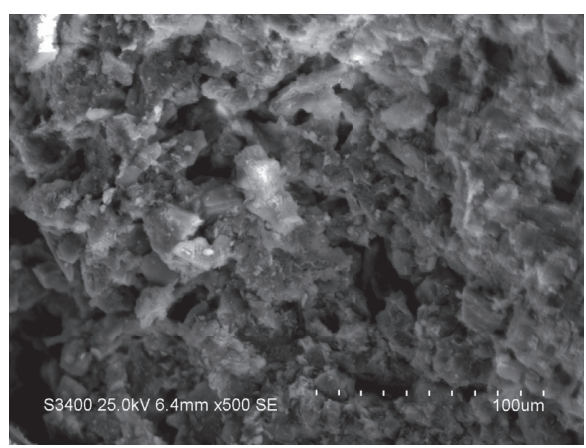

SEM image on vertical compacted surface

(d)

Figure 15: SEM images with different dry densities (500 times). (a) $\rho_{d}=1.70 \mathrm{~g} / \mathrm{cm}^{3}$. (b) $\rho_{d}=1.60 \mathrm{~g} / \mathrm{cm}^{3}$. (c) $\rho_{d}=1.50 \mathrm{~g} / \mathrm{cm}^{3}$. (d) $\rho_{d}=1.40 \mathrm{~g} / \mathrm{cm}^{3}$.

(1) The micropore structure of the compacted surface and vertical compacted surface was significantly different (Figure 15). The number of pores perpendicular to the compacted surface was greater than that on the compacted surface, and pore connectivity was better. This was the primary reason why the permeability coefficient of compacted loess parallel to the compacted surface was larger compared to the permeability perpendicular to the compacted surface.

(2) When $\rho_{d}=1.70 \mathrm{~g} / \mathrm{cm}^{3}$ (approaching the maximum dry density of $1.73 \mathrm{~g} / \mathrm{cm}^{3}$ ), the SEM images of the compacted surface showed that the soil particles were flaky and in face-to-face contact. Pores were mainly small pores and micropores between and in aggregates. Soil particles perpendicular to the compacted surface were primarily linear and in faceto-face contact. Pores were primarily composed of small pores between the aggregates. With the decreasing dry density, pore diameter between soil grains increased gradually, and pores were primarily composed of large and medium pores between aggregates $\left(\rho_{d}=1.5 \mathrm{~g} / \mathrm{cm}^{3}\right.$ and $\left.\rho_{d}=1.4 \mathrm{~g} / \mathrm{cm}^{3}\right)$.

(3) The number of pores on the compacted surface and perpendicular to the compacted surface increased gradually with the decreasing dry density. However, the difference of pore diameter and number on the compacted surface and perpendicular to the compacted surface decreased with the decreasing dry density, which revealed the reason why smaller dry densities correlate with smaller permeability anisotropy. On the contrary, when the dry density was higher, the permeability anisotropy was greater.

\section{Conclusions}

(1) The saturated permeability coefficient under confining pressure consolidation and $K_{0}$ consolidation of compacted loess was significantly affected by the initial dry density. With the increasing initial dry density, the saturated permeability coefficient decreased gradually, and with the increasing consolidation confining pressure, the saturated permeability coefficient decreased gradually. Through nonlinear regression analysis, the saturated permeability coefficient of compacted loess was determined to follow an exponential function related to the initial dry density. The fitting equation could be used to estimate the saturated permeability coefficient of compacted loess at different depths, providing a basis for water field analysis in loess filling engineering.

(2) The saturated permeability anisotropy under confining pressure consolidation and $K_{0}$ consolidation of compacted loess was quantitatively analyzed using the saturated permeability anisotropy ratio, which was linearly related to the initial dry density. 
(3) The saturated permeability coefficient of compacted loess under the $K_{0}$ consolidation condition was smaller than that under the confining pressure consolidation condition. Under the condition of $K_{0}$ consolidation, the connectivity of vertical and horizontal pores of compacted loess was weakened, the tortuosity was strengthened, and the void ratio was decreased. The saturated permeability coefficient ratio of compacted loess decreased with the decreasing dry density, and when the dry density was smaller, the permeability coefficient ratio was smaller under the same confining pressure.

(4) $K_{0}$ consolidation made the flake-, plate-, and needlelike particles in compacted loess rotate continuously parallel to the compaction surface, which enhanced the orientation of particles and led to the saturated permeability anisotropy increase. The research provides the basis for water field analysis in loess filling engineering.

(5) The microtest showed that the permeability anisotropy of compacted loess with different dry densities was mainly caused by the different pore structures in the direction of the vertical compaction surface and horizontal compaction surface.

\section{Abbreviations}

$K_{0}: \quad$ Coefficient of earth pressure at rest

$Q_{3}: \quad$ Late Pleistocene epoch

$G_{S}$ : Specific gravity of the soil particle

$\rho_{d}: \quad$ Dry density

$W_{L}: \quad$ Liquid limit

$W_{P}: \quad$ Plastic limit

$I_{p}: \quad$ Plasticity index

SEM: Scanning electron microscope

$\sigma_{1}: \quad$ Axial stress (major principal stress)

$\sigma_{3}$ : $\quad$ Confining pressure (minor principal stress)

$k_{s}: \quad$ Saturated permeability coefficient

$k_{s h}$ : Horizontal saturated permeability coefficient

$k_{s h}$ : Vertical permeability coefficient

$k_{K_{0}}$ : Saturated permeability coefficient under $K_{0}$ consolidation

$k_{\sigma_{c}}: \quad$ Saturated permeability coefficient under confining pressure consolidation

$r_{k s}: \quad$ Saturated permeability anisotropy ratio

$R_{k}$ : Saturated permeability coefficient ratio.

\section{Data Availability}

All data and models generated or used during this study are included within the article. All data used to support the findings of this study are available from the corresponding author upon request.

\section{Conflicts of Interest}

The authors declare that they have no conflicts of interest.

\section{Acknowledgments}

The authors would like to thank the team members of the key discipline of geotechnical engineering and the workers of the Geotechnical Engineering Laboratory. This work was supported by the National Natural Science Foundation of China (No. 51078309) and Foundation of Science and Technology Department of Henan Province of China (No. 172102310459).

\section{References}

[1] P. Bandini and S. Sathiskumar, "Effects of silt content and void ratio on the saturated hydraulic conductivity and compressibility of sand-silt mixtures," Journal of Geotechnical and Geoenvironmental Engineering, vol. 135, no. 12, pp. 1976-1980, 2009.

[2] R. D'Andrea and F. K. Boadu, "Hydraulic conductivity of soils from grain-size distribution:new models," Journal of Geotechnical and Geoenvironmental Engineering, vol. 127, no. 10, pp. 899-900, 2001.

[3] H. Han, D. Giménez, and A. Lilly, "Textural averages of saturated soil hydraulic conductivity predicted from water retention data," Geoderma, vol. 146, no. 1-2, pp. 121-128, 2008.

[4] T. Sathees, "Saturated hydraulic conductivity of poorly graded sands with nonplastic silt using a flexible wall permeameter," MS Thesis, New Mexico State University, Las Cruces, NM, USA, 2006.

[5] A. Cherif Taiba, Y. Mahmoudi, L. Hazout et al., "Evaluation of hydraulic conductivity through particle shape and packing density characteristics of sand-silt mixtures," Marine Georesources \& Geotechnology, vol. 37, no. 10, pp. 1175-1187, 2019.

[6] M. R. Muszynski and S. J. Vitton, "Particle shape estimates of uniform sands: visual and automated methods comparison," Journal of Materials in Civil Engineering, vol. 24, no. 2, pp. 194-206, 2012.

[7] M. Belkhatir, T. Schanz, and A. Arab, "Effect of fines content and void ratio on the saturated hydraulic conductivity and undrained shear strength of sand-silt mixtures," Environmental Earth Sciences, vol. 70, no. 6, pp. 2469-2479, 2013.

[8] Y. F. Li, "Relationship between the permeability and the porosity of Luochuan loess layer," Chinese Journal of Xi'an College of Geology, vol. 13, no. 2, pp. 60-64, 1991.

[9] L. Z. Wang, S. H. Ye, K. L. Shen et al., "Undrained shear strength of $K_{0}$ consolidated soft clays," Chinese Journal of Geotechnical Engineering, vol. 28, no. 8, pp. 970-977, 2006a.

[10] H. Wang, Z. R. Yue, and C. L. Ye, "Experimental investigation of permeability characteristics of intact and reshaped loess," Chinese Journal of Shijiazhuang Railway Institute (Natural Science), vol. 22, no. 2, pp. 20-22, 2009.

[11] F. Y. Liu, Z. Zhang, and D. Zhou, "Density saturation dependent air water permeability function of unsaturated loess," Chinese Journal of Rock Mechanics and Engineering, vol. 29, no. 9, pp. 1907-1914, 2010.

[12] Y. Z. Hao, T. H. Wang, and J. J. Wang, "Structural properties of unsaturated compacted loess for various sample moisture contents," Arabian Journal of Geosciences, vol. 12, no. 8, pp. 258-268, 2019.

[13] T. Y. Zhao, H. Y. Zhang, G. S. Yan et al., "Influence of penetrative conditions on permeability of modified loess soil 
by betonies," Chinese Hydrogeology and Engineering Geology, vol. 37, no. 5, pp. 108-112, 2010.

[14] H. T. Liu, A. J. Zhang, T. Duan et al., "The influence of alternate dry-wet on the strength and permeability of remolded loess," Hydro-science and Engineering, vol. 2010, no. 4, pp. 38-42, 2010.

[15] G. X. Zeng, X. N. Gong, and J. Y. Sheng, "Research on normally consolidated clay by $K_{0}$ consolidated shear test," Journal of Zhejiang University, vol. 21, no. 2, pp. 1-9, 1987.

[16] M. H. Zhao and X. Yu, Soil Mechanics and Foundations, Wuhan University of Technology Press, Wuhan, China, 2009.

[17] J. H. Atkinson, D. Richardson, and P. J. Robinson, "Compression and extension of $K_{0}$ normally consolidated Kaolin clay," Journal of Geotechnical Engineering, vol. 113, no. 12, pp. 1468-1481, 1986.

[18] H. T. Cheng, B. J. Liu, Y. L. Xie et al., " $K_{0}$ consolidation characteristics of compacted loess under continuous loading," Chinese Journal of Rock Mechanics and Engineering, vol. 26, no. S, pp. 3203-3208, 2007.

[19] F. Y. Chu, J. G. Zhu, P. Wang et al., "Study of deformation and strength characteristics of coarse grained soil under $K_{0^{-}}$ consolidation condition," Rock and Soil Mechanics, vol. 33, no. 6, pp. 1625-1630, 2012.

[20] M. S. Huang, X. Y. Song, and H. L. Qin, "Basal stability of braced excavations in $K_{0}$-consolidated soft clay by upper bound method," Chinese Journal of Geotechnical Engineering, vol. 30, no. 2, pp. 250-255, 2008.

[21] Y. Z. Jiu and M. S. Huang, "Coefficient of earth pressure at rest and undrained shear strength of $K_{0}$ over consolidated soft clays," Rock and Soil Mechanics, vol. 38, no. 4, pp. 954-957, 2017.

[22] X. L. Lu, J. G. Qian, and M. S. Huang, "Prediction of instability of $K_{0}$-consolidated saturated sands under undrained loading conditions," Chinese Journal of Geotechnical Engineering, vol. 37, no. 6, pp. 1010-1015, 2015.

[23] M. T. Luan, Z. D. Zhang, C. S. Xu et al., "Experimental studies of cyclic shear characteristic of sand under $K_{0}$ consolidation condition," Rock and Soil Mechanics, vol. 29, no. 9, pp. 2323-2328, 2008.

[24] P. W. Mayne and F. H. Kulhawy, " $K_{0}$-OCR relationship in soil," Journal of Geotechnical Engineering Division, ASCE, vol. 108, no. 6, pp. 851-872, 1982.

[25] M. S. Qi, C. X. Feng, Y. L. Xie et al., "Research of intact loess through continuous loading $K_{0}$ consolidation tests," Chinese Journal of Underground Space and Engineering, vol. 1, no. 3, pp. 370-373, 2005.

[26] Y. S. Leroueil, G. X. Cui, and W. H. Yang, "Prospect of experimental studies of height-pressure consolidation tests of soils in thick alluvium," Rock and Soil Mechanics, vol. 24, no. S, pp. 687-690, 2003.

[27] D. Y. Wang, W. Ma, and X. X. Chang, "Study on behavior of stress-strain for frozen soils subjected to $K_{0}$ consolidation by unloading triaxial shear tests," Chinese Journal of Rock Mechanical and Engineering, vol. 23, no. 8, pp. 1252-1256, 2004.

[28] T. H. Wang, J. Lu, and J. F. Zhang, "Experimental study of permeability coefficient of artificially compacted unsaturated loess considering influence of density," Chinese Journal of Rock Mechanics and Engineering, vol. 25, no. 11, pp. 23642368, 2006b.

[29] J. Y. Yuan, X. B. Wang, J. G. Dong et al., "Research on the strength and deformation of Shanghai clay soils under $K_{0}$ consolidation condition," Dam Observation and Geotechnical Tests, vol. 23, no. 4, pp. 29-32, 1999.
[30] C. L. Zhang, G. L. Jiang, Z. H. Dong et al., "Deformation response characteristics of undisturbed silty clay in $K_{0}$ consolidation state," Journal of Central South University (Science and Technology), vol. 45, no. 7, pp. 2378-2386, 2014.

[31] J. G. Zhu, E. Y. Ji, Z. R. Fang et al., "Comparison of triaxial text with $K_{0}$-consolidated and isotropically consolidated specimens of coarse grained soil," Journal of Disaster Prevention and Mitigation Engineering, vol. 33, no. 4, pp. 394-398, 2013.

[32] Standardization Administration of China (SAC, ), Ministry of Water Resources (1999) China National Standards GB/ T50123-1999, Standard for Soil Test Method, Beijing, China, 1999.

[33] P. Basak, "Soil structure and its effects on hydraulic conductivity," Soil Science, vol. 114, no. 6, pp. 417-422, 1972.

[34] S. Leroueil, G. Bouclin, F. Tavenas, L. Bergeron, and P. L. Bergeron, "Permeability anisotropy of natural clays as a function of strain," Canadian Geotechnical Journal, vol. 27, no. 5, pp. 568-579, 1990.

[35] R. J. Millington and J. P. Quirk, "Permeability of porous media," Nature, vol. 183, no. 2, pp. 387-388, 1959.

[36] F. Tavenas, P. Jean, P. Leblond, and S. Leroueil, "The permeability of natural soft clays. Part II: permeability characteristics," Canadian Geotechnical Journal, vol. 20, no. 4, pp. 645-660, 1983. 